This is an informal report intended primarily for internal or limited external distribution. The opinions and conclusions stated are those of the author and may or may not be those of the laboratory.

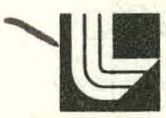

LAWRENCE LIVERMORE LABORATORY

University of California/Livermore, California

\title{
ESTIMATES OF SURFACE DEPOSITION OF RADIOACTIVITY AND \\ RADIATION DOSES RESULTING FROM PROPOSED NNTRP ACTIVITIES
}

Paul H. Gudiksen

Kendall R. Peterson

Apri1 1975

This report was prepared as an account of work
sponsored by the United States Government. Neither
the United States nor the United States Energy
Research and Development Administration, nor any of
their employees, nor any of their contractors,
subcontractors, or their employees, makes any
warranty, express or implied, or assumes any legal
liability or responsibility for the accuracy, completeness
or usefulnpss of any information, apparatus, product or
process disclosed, or represents that its use would not
infringe privately owned rights. 


\section{DISCLAIMER}

This report was prepared as an account of work sponsored by an agency of the United States Government. Neither the United States Government nor any agency Thereof, nor any of their employees, makes any warranty, express or implied, or assumes any legal liability or responsibility for the accuracy, completeness, or usefulness of any information, apparatus, product, or process disclosed, or represents that its use would not infringe privately owned rights. Reference herein to any specific commercial product, process, or service by trade name, trademark, manufacturer, or otherwise does not necessarily constitute or imply its endorsement, recommendation, or favoring by the United States Government or any agency thereof. The views and opinions of authors expressed herein do not necessarily state or reflect those of the United States Government or any agency thereof. 


\section{DISCLAIMER}

Portions of this document may be illegible in electronic image products. Images are produced from the best available original document. 


\section{FOREWORD}

As an aid to the reader, we have placed vertical lines in the right margin of the text to denote those places where this version differs from Revision 1. Changes in the tables have been underlined, except for Table 9 which is a new addition. The figures have not been changed. 


\section{INTRODUCTION}

The National Nuclear Test Readiness Program (NNTRP) has been developed by the $A E C$ and $D O D$ to maintain a state of readiness for the prompt resumption of atmospheric nuclear testing if circumstances warrant such resumption, for example, in the event of a U.S.S.R. abrogation of the Limited Test Ban Treaty. The NNTRP sets forth the objectives of the testing program and establishes a series of proposed nuclear tests that would be required to reach these objectives. Such proposed tests would be conducted at the Pacific Test Site.

Since the NNTRP is required to comply with the National Environmental Policy Act of 1970, it is necessary to assess the environmental consequences of the program. This report describes our contributions to this environmental assessment and includes ( 1 ) an estimation of the magnitude and distribution of radioactive debris deposited on the surface waters of the Pacific Ocean as a result of the test and (2) an estimation of the total person-rem to the Continental U.S. and Hawaiian Islands populations.

Since the proposed test series consists of a wide range of weapon yields to be detonated at various altitudes and the specific number and types of tests change with time according to national defense needs, a set of seven representative tests were selected for performing a parametric yield analysis at various burst locations and heights. The yields were selected to cover the "low intermediate", "intermediate", and "low megaton" ranges. The respective yields, detonation heights and ground 
zero locations are:

1. a $100 \mathrm{kt}$ air burst in the lower troposphere $-400 \mathrm{~km}$ south of Johnston Is land.

2. A $100 \mathrm{kt}$ air burst in the lower troposphere $-500 \mathrm{~km}$ east of Baker Is land.

3. A $100 \mathrm{kt}$ air burst in the upper troposphere - Kingman Reef.

4. A $500 \mathrm{kt}$ surface burst - $400 \mathrm{~km}$ south of Johnston Island.

5. A 1 Mt surface burst - Kingman Reef.

6. A 1 Mt air burst in the upper troposphere - Kingman Reef.

7. A 5 Mt air burst in the upper troposphere - Kingman Reef.

The following is a description of the atmospheric transport and diffusion models that were used in this work, the meteorological and radiological input data, and the results of the calculations.

\section{TRANSPORT, DIFFUSION AND DEPOSITION MODELS}

Air Bursts. When a nuclear device is detonated in the atmosphere, a radioactive cloud rises rapidly due to its excess thermal energy. Within about 10 minutes the cloud attains its maximum early time hgight which is primarily a function of yield. In a free air burst the fireball does not touch the surface, and, thus, essentially no material from the earth's surface is entrained into the cloud, and the particles carrying the radioactivity are so small that gravity has a negligible effect on their early vertical rise. Thus, for free air bursts, the transport, dispersion and deposition of radioactivity from the detonation point is determined 
primarily by the mean horizontal winds and by atmospheric diffusion processes. For debris clouds stabilized within the troposphere, these processes can be handled by the LLL two dimensional large cloud transport and diffusion code (2BPUFF). [1] This code treats the diffusion of a cylindrical cloud whose center height, thickness, radius, and radioactivity loading are known at cloud stabilization time. The initial cloud burden of activity in the horizontal and vertical are assumed to be Gaussian, but not isotropic. The horizontal dimensions of the cloud increase with time and are a function of the input meteorology and the initial cloud size. Vertical diffusion increases the cloud's vertical dimensions, but at a considerably lesser rate than that in the horizontal direction. Hence, the cloud changes with time from a relatively small cylindrical volume of highly concentrated activity to a very large disk with a low concentration of activity.

The model includes two mechanisms for depositing airborne particulates on the earth's surface: (1) that due to dry deposition, and (2) that due to precipitation scavenging (wet deposition). Dry deposition occurs as a result of such mechanisms as surface impaction, electrostatic phenomena, absorption and chemical interactions. The model uses the concept of a dry deposition velocity that operates on the surface air concentration to calculate the flux of material being deposited. An average value of $10 \mathrm{~mm} / \mathrm{s}^{[2]}$ was used, assuming a mean particle radius of $1 \mu \mathrm{m}$. Wet deposition, on the other hand, is derived by computing the vertical integral of radioactivity through the debris up to the top of the precipitating cloud as a function of time or distance downwind. This may then be transformed to activity per unit area. 
The 2BPUFF computer code has been verified by several nuclear rocket tests and nuclear cratering experiments conducted at NTS. The 1968 Schooner cratering experiment provided the most long-range measurements. The 2BPUFF code, using observed meteorology, replicated the observational results out to $300 \mathrm{~h}$ to within factors of 2 to 3. [3] The use of "average meteorology" for proposed events increases the error range by an amount related to the variability of the parameters.

Surface Bursts. The nuclear fireball touches the earth's surface and considerable surface material may be entrained into the fireball. In this case the calculation of downwind deposition is considerably more complicated since the mean particle size is significantly greater than in free air bursts. The activity associated with the large particles $(>10 \mu \mathrm{m})$, which have appreciable gravitational settling velocities, appears as close-in deposition while that associated with the small particles is transported downwind by the mean winds and spread by atmospheric diffusion processes as described previously. The close-in deposition pattern from a particular event may be calculated with the use of our KFOC code. [4] This code utilizes the stabilized cloud dimensions, activity vs. particle size distributions and the horizontal wind field as input parameters. The KFOC code is typical of all existing fallout codes we: are aware of in that it uses a vertical wind profile at a point and at a given time. This assumption is reasonable out to hundreds of kilometres. Our calculations have been extended to low deposition values at 3 to $4000 \mathrm{~km}$. The validity of our estimates at these distances are subject to errors in the orientation of the fallout pattern. The magnitude of such errors depends on the deviation of the vertical wind profile from the profile at ground zero. 
The code subdivides the initial debris cloud into discs of debris on the basis of debris on the basis of initial height of the cloud and of particle size. These discs are acted upon by the effects of atmospheric transport, lateral eddy diffusion, and gravitational settling during their fall from the initial debris height to the earth's surface. This permits a determination of the fraction of the initial cloud burden of activity that is deposited per unit area as a function of distance downwind from ground zero.

The KFOC computer code has been verified against a number of surface and buried nuclear bursts at NTS. [5] the calculated fallout patterns show reasonable agreement with measurements. Exposure rates were calculated along the "hot-line" for nine cases selected by Knox. Agreement with measurements is within a factor of eight for all points; the average error for each case is a factor of two or less.

Stratospheric Debris. An explosion of sufficient magnitude injects part of its activity into the stratosphere. For instance, a 5 Mt test would place virtually all its nuclear debris above the tropopause. This debris is transported worldwide within the stratosphere and "seeps" back into the troposphere to be deposited on the earth's surface at a slow rate. The maximum deposition occurs in middle latitudes during the spring season following the testing period. In this study we have used a global deposition mode ${ }^{[6]}$ that is based upon empirical data from the 1958 U.S. and U.S.S.R. test series. The model has been able to replicate, within factors of two or three, the measured annual deposition levels resulting from the 1967-62 U.S. and U.S.S.R. weapons test series. Depending 
upon total yield and height of burst, radioactivity from tests in the equatorial latitudes is placed into the troposphere and/or three stratospheric compartments. The model estimates global deposition on the surface as a function of time (up to six years following a test series) for 20 degree latitude bands.

\section{RADIOLOGICAL INPUT TO SEAFOOD CHAIN CALCULATIONS}

A list of approximately 50 radionuclides of potential interest for deposition over the ocean areas were supplied by Dr. A. Seymour. [7] These nuclides were ranked according to their relative radiological importance and the top 18 were selected for analysis. This ranking was performed by dividing the source term for each nuclide by the respective maximum permissible concentration in sea water (MPCC) value. Table 1 11sts the top 18 radionuclides according to their relative ranking along with the respective source term and MPCC values. Nuclides of the transuranic elements are not included since their relative importance is not within the top 18 nuclides. The source terms were obtained from the work by Drs. Y. $\mathrm{Ng}$ and H. Tewes ${ }^{[8]}$ and the MPCC values by Dr. J. Isaacs. [9] When using these data to derive the production of specific radionuclides for the particular events under consideration, an assumption of equal fission and fusion yields was made.

\section{INITIAL CLOUD DIMENSIONS AND METEOROLOGICAL DATA}

Input to the calculations includes the initial cloud base and top stabilization heights for each event under consideration. These data for the events of interest are shown in Table 2 and are based on U.S. nuclear testing experience. 
The wind data used in the calculations were based on work of Crutcher. [10] He presents six to seven year average wind speeds and directions for the Northern Hemisphere at the $850,700,500,300,200$ and 100 mbar levels. We assumed that the proposed tests would occur during the summer season. The average debris cloud center trajectories are shown in Figures 3-3 and 3-4 for the low troposphere air burst and surface burst near Johnston Island. These mean trajectories pass over or near Hawaii. Figure 3-5 depicts the average cloud-center trajectories for the low troposphere air burst near Baker Island. Two trajectories are shown because of the large vertical wind shear near the expected cloud center: Variations of stabllization height, within the error range of past $100 \mathrm{kt}$ bursts could cause average cloud-center trajectories that deviate as much as shown. The northern trajectory passes over Hawai $i$.

Fortunately, individual air trajectories typically show a large variation about the mean. An example of the extent of this variation has been provided by Ange11[11] He released from Japan about 200 constant level (9 to $11 \mathrm{~km}$ ) balloons over a two year period in the late 1950's and tracked their paths across the Pacific Ocean and North America. The points where these balloon trajectories crossed the longitude of Hawai extended from about Kingman Reef to northern Alaska. Crutcher ${ }^{[10]}$ shows that the upper air winds over the Pacific Test Site are much more variable, in all seasons, than the winds over Japan. Hence, even greater trajectory dispersion would be expected at the sites of the proposed tests.

During actual testing, practices used in the past would be followed. That is, detonations would only occur when the predicted trajectory, based on current observations and state-of-the-art prediction techniques, would minimize the dose to man. This procedure was followed successfully during the Cannikin exercise. 
The average cloud center trajectories shown in Figures $3-3$ to $3-5$ were used to calculate individual and population doses (presented in a later section). These potential doses should be considered as very conservative upper bounds, especially for Hawati.

No trajectories are shown for the events at Kingman Reef since essentialiy all of the resulting debris clouds will be injected into the stratosphere; the radioactivity from these tests will appear as long term global deposition with the exception of that portion of the activity associated with the large particulates generated by the $1.0 \mathrm{Mt}$ surface event which will react to gravitational forces and appear as close-in deposition (fallout).

For the estimation of wet deposition levels, it was necessary to estimate the fraction of the nuclear debris cloud that could reasonably be intersected by a rain cloud. With the assistance of Dr. J. Lovill (LLL), who examined a series of visible and infrared satellite maps, it was learned that nearly all of the activity in the nuclear debris clouds, of interest in this work, w1ll stay at altitudes where the temperature is below freezing. Hence, the only significant over ocean rainout will come from tropical rain storms that extend above the freezing level and intercept the nuclear debris clouds.

\section{CLOSE-IN DEPOSITION}

The close-in deposition patterns for the $500 \mathrm{kt}$ and $1.0 \mathrm{Mt}$ surface events are shown in Figs. 4 and 5 in relative units. Since the particles are acted upon by winds from cloud top to the surface, the orientation of the contours does not agree with the cloud center trajectories. which are 
at one altitude, for example Fig. 5 vs. Fig. 2. By means of the conversion factors listed in Table 3 , it is possible to transform the contours into actual deposition values $\left(\mathrm{pCi} / \mathrm{m}^{2}\right)$ for each of the 18 radionuclides of interest. These results are based upon the assumption that $50 \%$ of the total amount of activity produced in each event is associated with the large particle fraction and will appear in the close-in deposition pattern. This activity is also assumed to be associated with particulates having two log-normal size distributions. Ninety percent of the activity resides on particles with a geometric mean radius of $16 \mu \mathrm{m}$ and a standard geometric deviation of 2.3 and is homogeneously distributed throughout the entire cloud at stabilization time. The remaining $10 \%$ is situated within the lower fifth of the cloud on particles with a geometric mean radius of $245 \mu \mathrm{m}$ and a geometric standard deviation of 1.5. This distribution has resulted from the fitting of results of calculations with actual deposition data observed from Nevada Test Site events. The use of this distribution for a surface event on a coral reef is somewhat arbitrary; however, these are the only data avallable. These assumptions should lead to rather conservative deposition values in the case of several radionuclides such as ${ }^{131} \mathrm{I}$ and ${ }^{14} \mathrm{C}$ since a significant fraction of their activities are most likely not associated with particulates but are gaseous in nature; also, the refractory nuclides have gaseous precursors. 


\section{DRY DEPOSITION}

The dry deposition patterns for the two $100 \mathrm{kt}$ lower troposphere air bursts and the $500 \mathrm{kt}$ surface burst are shown in the attached figures: Areas $\mathrm{J}$ and $\mathrm{B}$ denote the Johnston Is land and Baker Island test areas, respectively. Since the calculated patterns are symmetric about the downwind axis, only half of the dry deposition patterns are shown. The ordinates are expanded relative to the abscissas. The downwind distance should be measured along the respective cloud center trajectory shown in Figs. 1-3. For the event east of Baker Island, the deposition patterns were only calculated along the northern trajectory; however, deposition along the southern trajectory would be expected to be similar in magnitude. Inspection of the data reveals that the distances are rather large. This is a result of dry deposition being a rather slow process because of the fine particulates involved. Several radionuclides have the same deposition values; this is due to our averaging process which was used whenever individual values were within $20 \%$ of each other.

\section{WET DEPOSITION}

As mentioned earlier, the activity deposited on the ocean surface by precipitation scavenging is a function of the fraction of the nuclear debris cloud that could reasonably be intercepted by a rain cloud. Since the only significant rainout of debris will come from tropical thunderstorms with ice-cloud tops, it was assumed that a height of eight kilometers is a reasonable maximum height for precipitation tops of ice clouds. [12] For the $100 \mathrm{kt}$ low altitude free air bursts and the $500 \mathrm{kt}$ surface burst, 
about $0.2 \%$ and $3 \times 10^{-4} \%$ of the nuclear debris clouds extend below $8 \mathrm{~km}$, respectively. The satellite maps indicate that, on the average, thunderstorms cover about $1 \%$ of the debris cloud area out to two standard deviations radius and up to 5 or 6 days downwind.

If we assume that all the radioactivity from the surface to an $8 \mathrm{~km}$ precipitation top is rained out in minutes, the ratio of the resultant wet deposition to the dry deposition is greater than $10^{7}$ during the first five days or $4000 \mathrm{~km}$ downwind. We have conservatively assumed that the $1 \%$ nuclear cloud rainout is centered at the debris cloud center. Table 4 shows as a function of distance and time downwind the actual enhancement factors that should be applied to the area of rainout. The radius of the precipitation area vs. downwind distance is shown both in Table 4 and by the heavy line near the bottom of the dry deposition patterns. The enhancement factors shown are essentially invariant with respect to spectfic nuclides because of our assumption of complete rainout below $8 \mathrm{~km}$.

\section{DOSE ESTIMATES}

The injections of radioactivity into the atmosphere from the proposed NNTRP tests contribute to the radiation dose received by populations situated downwind from the test sites. Estimates of the individual and population doses have been made for the Continental U.S. and the Hawaiian Islands. A population dose is the individual dose at a location multiplied by the population of that location. The population dose to the continental 
U.S. would be a seemingly large number due to a small individual dose times a large population. The largest population dose to the U.S. shown in the tables in this sub-section is about 0.04 of the population dose due to natural background terrestrial and cosmic radiation. Using the calculated surface air concentrations of specific radionuclides during cloud passage and the dry and wet deposition patterns in conjunction with food consumption data, it is possible to predict the whole body and organ doses resulting from the intake of the nuclides through the ingestion and inhalation pathways. The external dose resulting from the deposition of radioactivity on the earth's surfate may also be estimated from these data. For simplicity, the tests were divided into those that primarily inject debris into the troposphere (the two $100 \mathrm{kt}$ low altitude air bursts and the $500 \mathrm{kt}$ surface burst) and the remaining tests which inject most of their activity into the stratosphere.

Tropospheric Injections. The average surface air concentrations of activity over the U.S. during cloud passage and the average dry deposition patterns were calculated with the 2BPUFF code as described previously. Wet depositiontover the Continental U.S. was derived by estimating the fraction of the nuclear debris cloud that could reasonably be intersected by a rain bearing system. By the time the debris clouds from the three events pass over the U.S. their radii have increased to about $1600 \mathrm{~km}$ (two standard deviations from the cloud center). Thus, the debris cloud area then approximates that of the U.S. Assuming an average speed of $25 \mathrm{~m} / \mathrm{sec}$, the cloud center would traverse the U.S. in about four days. This period roughly corresponds to the average recurrence interval of precipitation throughout most of the U.S. Therefore, it is reasonable to assume that rainout will occur only 
once during the debris cloud's passage. Since, on the average, roughly onethird of the U.S. is under cloud cover at any one time, this provides a reasonable upper limit to the area of the debris cloud that could be subjected to precipitation scavenging. Thus, we have conservatively assumed that one-third of the debris cloud is subjected to rainout. This rainout area is assumed to be centered at the debris cloud center and all of the activity within this central region is scavenged to a height of $10 \mathrm{~km}$, a reasonable precipitation top of large scale rain clouds over the Continental U.S. [13] Thunderstorms are likely to be imbedded within these rain clouds, resulting in local "hot spots" of deposition; such "hot spots" are not treated in our dose calculations.

Our dose prediction analysis focuses on the inhalation, external dose and ingestion pathways. For the purpose of this discussion, the ingestion pathways are limited to the forage-cow-milk and pasture-meat pathways. These are relatively important because large areas can be grazed daily by cattle and both milk and beef are major constituents of the human diet. The dose contributed by the direct consumption of vegetation contaminated by dry and wet deposition is not included since a major fraction of this contamination may be removed by washing before consumption. The dose conversion constants that were used in this work are shown in Table 5. These were obtained from the data of $\mathrm{Ng}$ and Tewes, [8] and Tewes. [14]

The potential individual doses due to inhalation and dry deposition are negligible $\left(<10^{-10}\right.$ Rem in 30 years $)$ for the continental U.S. and Hawailan Island Populations. Thus, wet deposition is the only significant contributor to the dose. The 30-year whole body and 
bone doses due to the wet deposition of the most important radionuclides over the Continental U.S. are shown in Table 6 for the external dose, forage-cow-milk, and pasture-meat pathways. A review of the table reveals that the most significant contributor is the external dose $\left(8 \times 10^{-3}\right.$ Rem $)$ from gross fission products deposited on the earth's surface. The total individual 30 year whole body dose commitment from these pathways is about 10 mrem. Since we assumed rainout occurs over an area that approximates one-third of that of the U.S., it would be also reasonable to assume that one-third of the U.S. population $\left(7 \times 10^{7}\right.$ people $)$ would be exposed to these average dose levels. Thus, the total continental U.S. population dose commitment is about $7 \times 10^{5}$. person-rem. Not shown in the table is the adult thyroid dose due to I-131 via the milk pathway which is estimated to be 0.2 Rem. The dose due to tritium is difficult to ascertain because of the complex behavior of tritium in the environment. However, Martin and Koranda ${ }^{[15]}$ have estimated that the tritium whole body dose is approximately 37-370 times less than that due to the external dose from fission products.

Similarly the potential 30 year whole body and bone doses resulting from wet deposition over the Hawaijan Islands are shown in Table 7. These doses were derived on the basis of the same living patterns as those used in Table 6. Since our calculations assume that rainout over the Pacific Ocean occurs only over a relatively small area near the center of the nuclear debris cloud, the only events that contribute to the Hawallan Island population dose are the $100 \mathrm{kt}$ air burst near. Baker Island and the $500 \mathrm{kt}$ surface burst near Johnston Island whose trajectories pass directly over Hawaii. The surface deposition levels were estimated on the basis of 
the attached dry deposition patterns and rainout enhancement factors of $2 \times 10^{9}$ and $2 \times 10^{7}$ for the Baker Is land and the Johnston Is Iand events, respectively. A review of the results indicates that the Individual whole body and bone doses are about a factor of three greater than the corresponding Continental U.S. values to give a total whole body dose commitment of about 30 mrem. Assuming debris rainout occurs over most of the Hawaijan Islands, approximately $7 \times 10^{5}$ people would be exposed. Thus, the total Hawaiian population dose commitment would be about $2 \times 10^{4}$ person-rem.

If the debris cloud generated near Baker Island should follow the southern trajectory, it would most likely pass over several inhabited islands within the South Pacific. The potential dry and wet surface deposition levels would be expected to be similar in magnitude to those shown for the northern trajectory. Thus, if the cloud were to pass directly over an inhabited island within two days post detonation, the potential 30 year external whole body dose would be of the order of 0.1-1 Rem if rainout occurs. Assuming vegetables and fruit are washed before consumption, the internal doses would probably be less than the external dose. The pathways considered for the U.S. populations would be inappropriate since life styles are considerably different in the South Pacific. Without a detailed analysis of dietary habits (which differ between island groups) and soil-root uptake studies, it would be difficult to quantify the internal doses.

Stratospheric Injections. A significant fraction of the radioactivity produced by the $1 \mathrm{Mt}$ surface burst and essentially all of the activity; produced by the $100 \mathrm{kt}, . \mathrm{Mt}$, and $5 \mathrm{Mt}$ air bursts over Kingman Reef was assumed to be injected into the equatorial stratosphere during the summer season. This debris diffuses polewards within both hemispheres; however, most of it remains within the Northern Hemisphere. A major fraction of the debris enters the troposphere at middle latitudes $\left(30^{\circ}\right.$ - 
$50^{\circ} \mathrm{N}$ ) and is deposited on the earth!'s surface with a residence half-time of 9-12 months.

The individual and U.S. population doses resulting from the deposition of this stratospheric debris at middle latitudes are shown in Table 8. These doses were estimated on the basis of the activity being deposited over a six year period following injection. Because of the long transport times, the long lived nuclides such as $\mathrm{Sr}-90$ and $\mathrm{Cs}-137$ contribute most significantly to the total dose. A review of the dose estimates reveals that the 30 year external whole body dose commitment is about $60 \mathrm{mrem}$. Since the activity is assumed to be homogeneously deposited within the $30^{\circ}-50^{\circ} \mathrm{N}$ latitude band the entire U.S. population would be exposed to these dose levels. Thus, the total U.S. population dose commitment would approximate $1 \times 10^{7}$ person-rem.

The stratospheric debris would gradually deposit over the entire earth's surface. For this reason we have calculated 30-year individual and population doses for 20-degree latitude bands. For the food pathways, we have assumed that the entire world has dietary habits similar to those in the U.S. In addition, no account is taken of shielding or weathering of the deposited activity. Table 9 presents our global dose estimates. Within each latitude bant, external dose from gross fission products yields the largest contribution to the total dose. Doses from ${ }^{137}$ Cs via the pasture-meat pathway are the second greatest contributor. ${ }^{106}$ Ru gives the smallest.doses, but the whole body doses from the pasture-meat pathway are comparable to ${ }^{90} \mathrm{Sr}$ doses via the same path. 
The population doses are greatest in the Northern Hemisphere, due principally to the fact that only $10 \%$ of the world's population reside in the Southern Hemisphere. Note that the global natural background population dose, assuming each person receives 0.1 Rem/year, is 50 times the population dose from the proposed NNTR.P tests. 
TABLE 1

RANKING OF RADIONUCLIDES

(SEAFOOD PATHWAY)

\begin{tabular}{|c|c|c|c|}
\hline $\begin{array}{l}\text { RELAT IVE } \\
{ }^{1} \\
\text { RANKING }\end{array}$ & NUCL IDE & $\begin{array}{l}\text { SOURCE }^{2} \\
(\mathrm{Ci} / \mathrm{Mt})\end{array}$ & $\begin{array}{c}\mathrm{MPCC} \\
(\mu \mathrm{Ci} / \mathrm{Kg})\end{array}$ \\
\hline 1.0 & Ru-103 & $4 \times 10^{7}$ & $2 \times 10^{-5}$ \\
\hline$\underline{0.83}$ & Tc-99 & $1 \times 10^{8}$ & $6 \times 10^{-5}$ \\
\hline 0.67 & Te-127m & $4 \times 10^{4}$ & $3 \times 10^{-8}$ \\
\hline 0.50 & Ru-106 & $2 \times 10^{6}$ & $2 \times 10^{-6}$ \\
\hline 0.25 & $\mathrm{Cu}-64$ & $3 \times 10^{6}$ & $6 \times 10^{-6}$ \\
\hline 0.23 & La-140 & $9 \times 10^{7}$ & $2 \times 10^{-4}$ \\
\hline$\underline{0.13}$ & $P-32$ & $8 \times 10^{5}$ & $3 \times 10^{-6}$ \\
\hline 0.08 & $\mathrm{Ba}-140$ & $1 \times 10^{8}$ & $6 \times 10^{-4}$ \\
\hline 0.05 & $I-131$ & $2 \times 10^{8}$ & $2 \times 10^{-3}$ \\
\hline 0.04 & Co-58 & $8 \times 10^{5}$ & $1 \times 10^{-5}$ \\
\hline 0.02 & $\mathrm{Ce}-141$ & $4 \times 10^{7}$ & $9 \times 10^{-4}$ \\
\hline$\underline{0.02}$ & $M n-54$ & $3 \times 10^{5}$ & $7 \times 10^{-6}$ \\
\hline$\underline{0.02}$ & Ce-144 & $4 \times 10^{6}$ & $1 \times 10^{-4}$ \\
\hline$\underline{0.02}$ & $Z r-95$ & $2 \times 10^{7}$ & $6 \times 10^{-4}$ \\
\hline 0.008 & $\mathrm{Fe}-55$ & $6 \times 10^{5}$ & $4 \times 10^{-5}$ \\
\hline 0.005 & $\mathrm{Fe}-59$ & $3 \times 10^{4}$ & $3 \times 10^{-6}$ \\
\hline$\underline{0.003}$ & $C-14$ & $4 \times 10^{4}$ & $7 \times 10^{-6}$ \\
\hline 0.002 & Co-57 & $2 \times 10^{5}$ & $5 \times 10^{-5}$ \\
\hline
\end{tabular}

1. Ru-103 is taken as unity.

2. Values are decay-corrected to detonation time. 
TABLE 2

INITIAL CLOUD DIMENSIONS

\begin{tabular}{|c|c|c|c|c|}
\hline $\begin{array}{r}\text { YIELD } \\
(\mathrm{Kt}) \\
\end{array}$ & $\begin{array}{l}\text { HEIGHT OF } \\
\text { BURST }(m)\end{array}$ & $\begin{array}{l}\text { CLOUD CENTER } \\
\text { HEIGHT (m) }\end{array}$ & $\begin{array}{c}2 \sigma \\
\text { RADIUS } \\
(m) \\
\end{array}$ & $\begin{array}{c}2_{\sigma} \\
\text { THICKNESS } \\
\text { (m) } \\
\end{array}$ \\
\hline 100 & $\begin{array}{l}\text { Lower } \\
\text { Troposphere }\end{array}$ & 12000 & 7500 & 5600 \\
\hline 100 & $\begin{array}{l}\text { Upper } \\
\text { Troposphere }\end{array}$ & 20000 & 7500 & 5600 \\
\hline 500 & Surface & 16000 & 12000 & 6500 \\
\hline 1000 & Surface & 18000 & 18000 & 9000 \\
\hline 1000 & $\begin{array}{l}\text { Upper } \\
\text { Troposphere }\end{array}$ & 26000 & 18000 & 9000 \\
\hline 5000 & $\begin{array}{l}\text { Upper } \\
\text { Troposphere }\end{array}$ & 30000 & 31000 & 11000 \\
\hline
\end{tabular}


TABLE 3

CONVERSION FACTORS TO BE APPLIED -

TO UNIT CONTOUR OF FIGS. 4 and 5.

\section{RADIONUCLIDE}

Ru-103

TC-99

Te-127m

$\mathrm{Ru}-106$

$\mathrm{Cu}-64$

$\underline{\text { La- } 140}$

P-32

$B a \ddot{a}-140$

I-131

Co-58

$\mathrm{Ce}-\mathrm{T} 4 \mathrm{1}$

$\mathrm{Mn}-54$

Ce- 144

Zr-95

$\mathrm{Fe}-55$

$\mathrm{Fe}-59$

C $-14^{\circ}$

Co-57
VALUE OF UNIT CONTOUR $\left(\mathrm{pCi} / \mathrm{m}^{2}\right)$

$8 \times 10^{6}$

$2 \times 10^{7}$

$8 \times 10^{3}$

$4 \times 10^{5}$

$6 \times 10^{5}$

$\frac{2 \times 10^{7}}{2 \times 10^{5}}$

$2 \times 10^{7}$

$4 \times 10^{7}$

$2 \times 10^{5}$

$8 \times 10^{6}$

$6 \times 10^{43}$

$8 \times 10^{5}$

$4 \times 1.0^{6}$

$1 \times 10^{5}$

$6 \times 10^{3}$

$8 \times 10^{3}$

$4 \times 10^{4}$ 
TABLE 4

ENHANCEMENT FACTORS FOR RAINOUT FROM SURFACE AND AIR BURSTS

\begin{tabular}{|c|c|c|c|c|}
\hline & & Area B. & \multicolumn{2}{|c|}{ Area J } \\
\hline & & $100 \mathrm{kt}$ & $100 \mathrm{kt}$ & $500 \mathrm{kt}$ \\
\hline Day 1 & $\begin{array}{l}\text { Distance }(\mathrm{km}) \\
\text { Radius }(\mathrm{km}) \\
\text { Area }\left(\mathrm{km}^{2}\right) \\
\text { Enhancement } \\
\quad \text { Factor }\end{array}$ & $\begin{array}{l}900 \\
3.0 \\
28 \\
4 \times 10^{10}\end{array}$ & $\begin{array}{c}1000 \\
10 \\
310 \\
2 \times 10^{10}\end{array}$ & $\begin{array}{c}900 \\
3.2 \\
32 \\
2 \times 10^{7}\end{array}$ \\
\hline Day 2 & $\begin{array}{l}\text { Distance ( } \mathrm{km}) \\
\text { Radius }(\mathrm{km}) \\
\text { Area (km2) } \\
\text { Enhancement } \\
\quad \text { Factor }\end{array}$ & $\begin{array}{l}1700 \\
6.5 \\
130 \\
3 \times 10^{10}\end{array}$ & $\begin{array}{r}2100 \\
27 \\
2300 \\
7 \times 10^{9}\end{array}$ & $\begin{array}{l}1700 \\
8.6 \\
230 \\
2 \times 10^{7}\end{array}$ \\
\hline Day 3 & $\begin{array}{l}\text { Distance }(\mathrm{km}) \\
\text { Radfus }(\mathrm{km}) \\
\text { Area }\left(\mathrm{km}^{2}\right) \\
\text { Enhancement } \\
\text { Factor }\end{array}$ & $\begin{array}{l}2600 \\
11 \\
360 \\
2 \times 10^{10}\end{array}$ & $\begin{array}{r}3700 \\
50 \\
7700 \\
3 \times 10^{9}\end{array}$ & $\begin{array}{r}2600 \\
75 \\
710 \\
2 \times 10^{7}\end{array}$ \\
\hline Day 4 & $\begin{array}{l}\text { Distance }(\mathrm{km}) \\
\text { Radius }(\mathrm{km}) \\
\text { Area }(\mathrm{km} 2) \\
\text { Enhancement } \\
\quad \text { Factor }\end{array}$ & $\begin{array}{l}3500 \\
16 \\
800 \\
4 \times 10^{9}\end{array}$ & $\begin{array}{c}4100 \\
75 \\
19000 \\
2 \times 10^{9}\end{array}$ & $\begin{array}{r}3500 \\
22 \\
1500 \\
2 \times 10^{7}\end{array}$ \\
\hline Day 5 & $\begin{array}{l}\text { Distance }(\mathrm{km}) \\
\text { Radius }(\mathrm{km}) \\
\text { Area }\left(\mathrm{km}^{2}\right) \\
\text { Enhancement } \\
\text { Factor }\end{array}$ & $\begin{array}{l}4300 \\
27 \\
2300 \\
9 \times 10^{8}\end{array}$ & $\begin{array}{c}5200 \\
100 \\
33000 \\
8 \times 10^{8}\end{array}$ & $\begin{array}{l}4300 \\
32 \\
3200 \\
2 \times 10^{7}\end{array}$ \\
\hline
\end{tabular}


TABLE 5. Dose Conversion Constants for various pathways.

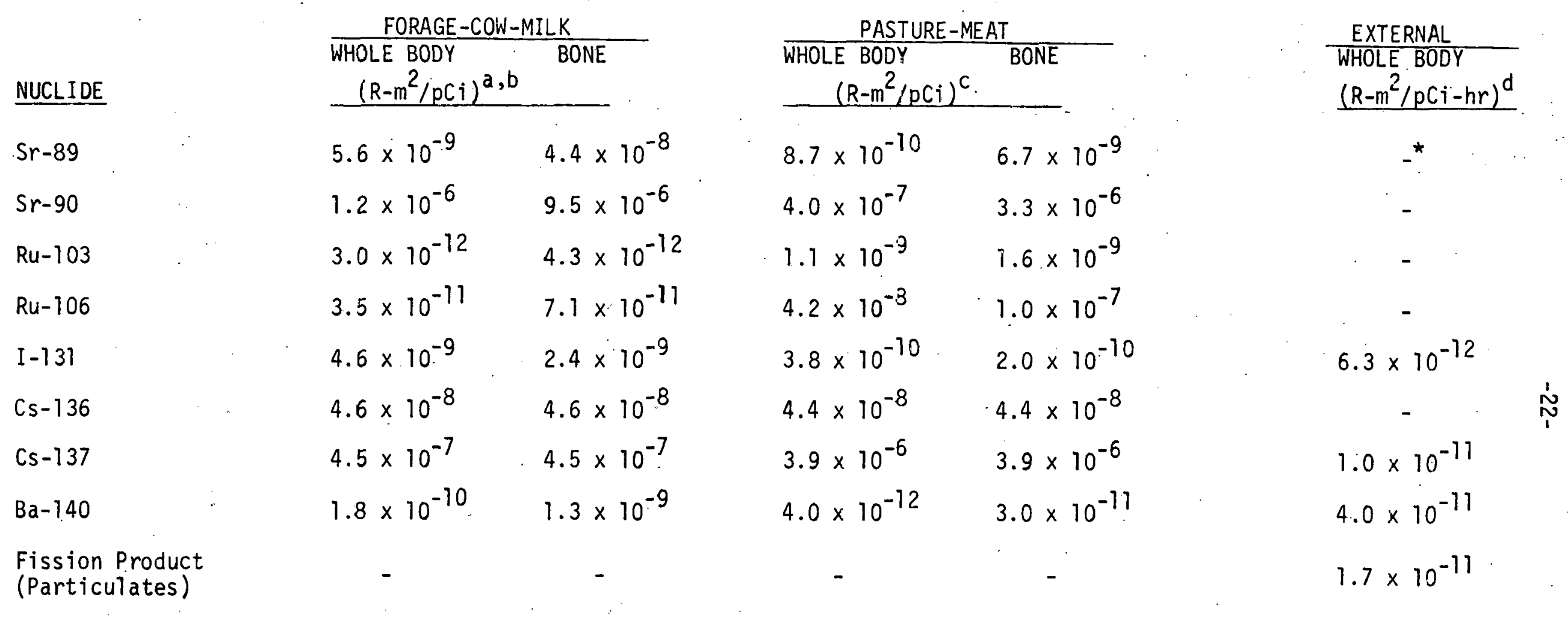
assumes the activity deposited on pasture is continuously ingested by the grazing cow which utilizes $45 \mathrm{~m}^{2}$ of
pasture daily.

b. Milk is assumed to be consumed at the rate of 1 liter/day.

c. Values are based upon a daily meat intake of $300 \mathrm{~g}$ for a six month period immediately following the maximum concentrations of radioactivity in the muscle.

d. One meter above the ground with no shieiding.

* $(-)$ not calculated 
TABLE 6. Estimated 30 year dose commitment to the Continental U.S. population from the most significant radionuclides produced by the two $100 \mathrm{kt}$ air bursts and the $500 \mathrm{kt}$ surface burst.

NUCLIDE

Sr-89

$\operatorname{sr}-90$

Ru-103

$\mathrm{Ru}-106$

$\mathbf{I}-131$

Cs-136

Cs-137

$\mathrm{Ba}-140$

Fission Products (Particulates)

Total Individual Dose Commitment

Population Dose Commitment (person-rem)

\section{FORAGE-COW-MILK DOSE (REm)} WHOLE BODY
$4 \times 10^{-5}$
$4 \times 10^{-5}$
$<10^{-7}$
$3 \times 10^{-4}$
$3 \times 10^{-8}$
$4 \times 10^{-4}$
$2 \times 10^{-4}$
$4 \times 10^{-5}$
$5 \times 10^{-6}$
$3 \times 10^{-4}$
$<10^{-7}$
$5 \times 10^{-8}$
$2 \times 10^{-4}$
$2 \times 10^{-4}$
$4 \times 10^{-5}$
$4 \times 10^{-5}$

BONE

$7 \times 10^{-4}$

$1 \times 10^{-3}$

$5 \times 10^{4}$

\section{PASTURE-MEAT DOSE (Rem)}

WHOLE BOUY

$5 \times 10^{-6}$

BONE

$1 \times 10^{-5}$

$2 \times 10^{-5}$

$3 \times 10^{-5}$

$3 \times 10^{-5}$

$2 \times 10^{-4}$

$3 \times 10^{-4}$

$1 \times 10^{-7}$

$4 \times 10^{-5}$

$1 \times 10^{-4}$

$2 \times 10^{-5}$

$8 \times 10^{-5}$

$2 \times 10^{-5}$

$2 \times 10^{-4}$

$3 \times 10^{-4}$

$9 \times 10^{-7}$

$6 \times 10^{-4}$

$8 \times 10^{-4}$

$4 \times 10^{4}$
$2 \times 10^{-4}$

$2 \times 10^{-4}$

$8 \times 10^{-4}$

$8 \times 10^{-3}$

EXTERNAL DOSE (Rem)

WHOLE BODY

0

0

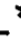

$8 \times 10^{-3}$

$6 \times 10^{5}$ 
TABLE 7. Estimated 30 year dose commitment to the Hawaijan Islands population from the most significant radionuclides produced by the $100 \mathrm{kt}$ air burst near Baker. Island and the $500 \mathrm{kt}$ surface burst near Johnston Island.

\section{NUCLIDE}

Sr-89

Sr -90

Ru-103

Ru-106

I-131

Cs-136

Cs-137

$\mathrm{Ba}-140$

Fission Product (Particulates)

Total Individual Dose (Commitment)

Population Dose Commitment (person-rem)
FORAGE-COW-MILK DOSE (Rem) WHOLE BODY

$1 \times 10^{-4}$

BONE

$1 \times 10^{-4}$

$7 \times 10^{-4}$

$<10^{-7}$

$8 \times 10^{-4}$

$2 \times 10^{-8}$

$<10^{-7}$

$1 \times 10^{-3}$

$1 \times 10^{-7}$

$5 \times 10^{-4}$

$4 \times 10^{-4}$

$5 \times 10^{-4}$

$1 \times 10^{-4}$

$1 \times 10^{-4}$

$3 \times 10^{-5}$

$2 \times 10^{-4}$

$2 \times 10^{-3}$

$2 \times 10^{-3}$

$1 \times 10^{3}$
PASTURE-MEAT DOSE (Rem.)

WHOLE BODY

$1 \times 10^{-5}$

BONE

$3 \times 10^{-5}$

$1 \times 10^{-4}$

$3 \times 10^{-5}$

$3 \times 10^{-4}$

$1 \times 10^{-4}$

$8 \times 10^{-5}$

$5 \times 10^{-4}$

$8 \times 10^{-4}$

$5 \times 10^{-7}$

$5 \times 10^{-5}$

$2 \times 10^{-4}$

$4 \times 10^{-5}$

$5 \times 10^{-4}$

$8 \times 10^{-4}$

$5 \times 10^{-6}$

$7 \times 10^{2}$
$4 \times 10^{-4}$

$2 \times 10^{-3}$

$3 \times 10^{-2}$

$3 \times 10^{-2}$

EXTERNAL DOSE (Rem)

WHOLE BODY

0

0

$3 \times 10^{-4}$

$\stackrel{1}{N}$

$2 \times 10^{4}$ 
TABLE 8. Estimated 30 year dose comitment to the U.S. population from the most significant radionuclides produced by the tests at Kingman Reef.

NUCLIDE

$5 \dot{r}-89$

Sr-90

Ru-103

Ru-106

$[-137$

Cs -136

Cs -137

$\mathrm{Ba}-140$

Fission Products (Particulates)

Total Individual Dose Commitment

U.S. Population Dose Commitment (person-rem) $\frac{\text { FORAGE-COW-MILK DOSE (Rem) }}{\text { WHOLE BODY }}$

$2 \times 10^{-5}$

$2 \times 10^{-4}$

$\frac{1 \times 10^{-3}}{<10^{-7}}$

$\frac{1 \times 10^{-2}}{<10^{-7}}$

$3 \times 10^{-7}$

$6 \times 10^{-7}$

$<10^{-7}$

$<10^{-7}$

$\frac{1 \times 10^{-3}}{<10^{-7}}$

$<10^{-7}$

$<10^{-7}$

$\frac{1 \times 10^{-3}}{<10^{-7}}$

$2 \times 10^{-3} \quad 1 \times 10^{-2}$

$4 \times 10^{5}$
PASTURE-MEAT DOSE (Rem)

WHOLE BODY BONE

$4 \times 10^{-6}$

$3 \times 10^{-5}$

$\underline{4} \times 10^{-4}$

$3 \times 10^{-3}$

$6 \times 10^{-6}$

$9 \times 10^{-6}$

$4 \times 10^{-4}$

$<10^{-7}$

$<10^{-7}$

$\underline{9} \times 10^{-3}$

$<10^{-7}$

$\underline{9} \times 10^{-4}$

$<10^{-7}$

$<10^{-7}$

$\underline{9} \times 10^{-3}$

$<10^{-7}$

$3 \times 10^{6}$
$1 \times 10^{-3}$ $<10^{-7}$

$6 \times 10^{-2}$

$6 \times 10^{-2}$

EXTERNAL DOSE (Rem) WHOLE BODY

0

0

$<10^{-7}$

$1 \times 10^{7}$ 
$-26-$

Thele 9. Estimaced 30 year global doses from dobris placed into the stratosphero by propused tests.

\begin{tabular}{|c|c|c|c|c|c|c|c|c|}
\hline $\begin{array}{l}\text { Lotitude and } \\
\text { Pathmay }\end{array}$ & $\begin{array}{l}5 r-90 \\
(\text { Rẹm) }\end{array}$ & $\begin{array}{l}\text { Ru- } 106 \\
\text { (P.cn) }\end{array}$ & $\begin{array}{l}C_{3}-137 \\
(\operatorname{Ren})\end{array}$ & $\begin{array}{l}\text { Gross EP } \\
\text { (P.en) }\end{array}$ & $\begin{array}{l}\text { Total } \\
\text { Individual } \\
\text { Dose } \\
\text { (P.em) }\end{array}$ & $\begin{array}{l}\text { Est. } 1974 \\
\text { Population }\end{array}$ & $\begin{array}{l}\text { Population } \\
\text { Dose } \\
\text { (Person-Rem) }\end{array}$ & $\begin{array}{l}\text { 30y Matural } \\
\text { Background } \\
\text { Poo. Dosed } \\
\text { (Person-Rem) }\end{array}$ \\
\hline $\begin{array}{c}70-90 \mathrm{H} \\
\text { FCH WB } \\
\text { Bone } \\
\text { PH WB } \\
\text { Bone } \\
\text { Ext. Dose (KB) } \\
\end{array}$ & $\begin{array}{c}2 \times 10^{-4} \\
2 \times 10^{-3} \\
8 \times 10^{-5} \\
7 \times 10^{-4} \\
0\end{array}$ & $\begin{array}{c}6 \times 10^{-8} \\
1 \times 10^{-7} \\
7 \times 10^{-5} \\
2 \times 10^{-4} \\
8\end{array}$ & $\begin{array}{l}2 \times 10^{-4} \\
2 \times 10^{-4} \\
2 \times 10^{-3} \\
2 \times 10^{-3} \\
2 \times 10^{-4}\end{array}$ & $\begin{array}{c}- \\
- \\
- \\
- \\
1 \times 10^{-2}\end{array}$ & $\begin{array}{l}4 \times 10^{-4} \\
2 \times 10^{-3} \\
2 \times 10^{-3} \\
3 \times 10^{-3} \\
1 \times 10^{-2}\end{array}$ & c & $\begin{array}{l}- \\
- \\
- \\
-\end{array}$ & $\begin{array}{l}- \\
- \\
- \\
-\end{array}$ \\
\hline $\begin{array}{l}50-70 \mathrm{~N} \\
\text { FCH WB } \\
\text { Bone } \\
\text { PH WB } \\
\text {. Bone } \\
\text { Ext. Dose (W/) }\end{array}$ & $\begin{array}{c}9 \times 10^{-4} \\
7 \times 10^{-3} \\
3 \times 10^{-4} \\
3 \times 10^{-3} \\
0\end{array}$ & $\begin{array}{c}2 \times 10^{-7} \\
5 \times 10^{-7} \\
3 \times 10^{-4} \\
7 \times 10^{-4} \\
1\end{array}$ & $\begin{array}{l}8 \times 10^{-4} \\
8 \times 10^{-4} \\
7 \times 10^{-3} \\
7 \times 10^{-3} \\
8 \times 10^{-4}\end{array}$ & $\begin{array}{c}- \\
- \\
- \\
- \\
5 \times 10^{-2}\end{array}$ & $\begin{array}{l}2 \times 10^{-3} \\
8 \times 10^{-3} \\
8 \times 10^{-3} \\
1 \times 10^{-2} \\
5 \times 10^{-2}\end{array}$ & $3.3 \times 10^{8}$ & $\begin{array}{l}7 \times 10^{5} \\
3 \times 10^{6} \\
3 \times 10^{6} \\
3 \times 10^{6} \\
2 \times 10^{7}\end{array}$ & $\begin{array}{c}- \\
= \\
= \\
1 \times 10^{9}\end{array}$ \\
\hline $\begin{array}{l}30-50 \text { i } \\
\text { FCK WB } \\
\text { Bone } \\
\text { PH WB } \\
\text { Bone } \\
\text { Ext. Dose (WB) }\end{array}$ & $\begin{array}{c}1 \times 10^{-3} \\
1 \times 10^{-2} \\
4 \times 10^{-4} \\
3 \times 10^{-3} \\
0\end{array}$ & $\begin{array}{c}3 \times 10^{-7} \\
6 \times 10^{-7} \\
4 \times 10^{-4} \\
9 \times 10^{-4} \\
\end{array}$ & $\begin{array}{l}1 \times 10^{-3} \\
1 \times 10^{-3} \\
9 \times 10^{-3} \\
9 \times 10^{-3} \\
1 \times 10^{-3}\end{array}$ & $\begin{array}{c}- \\
- \\
- \\
- \\
6 \times 10^{-2}\end{array}$ & $\begin{array}{l}2 \times 10^{-3} \\
1 \times 10^{-2} \\
1 \times 10^{-2} \\
1 \times 10^{-2} \\
6 \times 10^{-2} \\
\end{array}$ & $1.5 \times 10^{9}$ & $\begin{array}{l}3 \times 10^{6} \\
2 \times 10^{7} \\
2 \times 10^{7} \\
2 \times 10^{7} \\
9 \times 10^{7}\end{array}$ & $\begin{array}{c}- \\
- \\
- \\
= \\
5 \times 10^{9}\end{array}$ \\
\hline $\begin{array}{l}10-30 N \\
\text { FCK wB } \\
\text { Bone } \\
\text { PH WB } \\
\text { Bohe } \\
\text { Ext. Dose (WB) }\end{array}$ & $\begin{array}{c}6 \times 10^{-4} \\
4 \times 10^{-3} \\
2 \times 10^{-4} \\
2 \times 10^{-3} \\
0\end{array}$ & $\begin{array}{c}1 \times 10^{-7} \\
3 \times 10^{-7} \\
2 \times 10^{-4} \\
4 \times 10^{-4} \\
1\end{array}$ & $\begin{array}{l}5 \times 10^{-4} \\
5 \times 10^{-4} \\
4 \times 10^{-3} \\
4 \times 10^{-3} \\
5 \times 10^{-4}\end{array}$ & $\begin{array}{c}- \\
- \\
- \\
- \\
3 \times 10^{-2}\end{array}$ & $\begin{array}{l}1 \times 10^{-3} \\
5 \times 10^{-3} \\
4 \times 10^{-3} \\
6 \times 10^{-3} \\
3 \times 10^{-2}\end{array}$ & $1.4 \times 10^{9}$ & $\begin{array}{l}1 \times 10^{6} \\
7 \times 10^{6} \\
6 \times 10^{6} \\
8 \times 10^{6} \\
\times 10^{7}\end{array}$ & $\begin{array}{c}- \\
- \\
= \\
- \\
4 \times 10^{9}\end{array}$ \\
\hline $\begin{array}{c}10 \mathrm{~s}-10 \mathrm{~W} \\
\text { FCH WB } \\
\text { Bone } \\
\text { PH wo } \\
\text { bone } \\
\text { Ext. Dose (WB) }\end{array}$ & $\begin{array}{l}5 \times 10^{-4} \\
4 \times 10^{-3} \\
2 \times 10^{-4} \\
1 \times 10^{-3} \\
0\end{array}$ & $\begin{array}{c}1 \times 10^{-7} \\
3 \times 10^{-7} \\
2 \times 10^{-4} \\
4 \times 10^{-4} \\
0\end{array}$ & $\begin{array}{l}4 \times 10^{-4} \\
4 \times 10^{-1} \\
3 \times 10^{-3} \\
3 \times 10^{-3} \\
4 \times 10^{-4}\end{array}$ & $\begin{array}{c}- \\
- \\
- \\
- \\
2 \times 10^{-2}\end{array}$ & $\begin{array}{l}9 \times 10^{-4} \\
4 \times 10^{-3} \\
3 \times 10^{-3} \\
4 \times 10^{-3} \\
2 \times 10^{-2}\end{array}$ & $4.2 \times 10^{8}$ & $\begin{array}{l}1 \times 10^{5} \\
2 \times 10^{6} \\
1 \times 10^{6} \\
2 \times 10^{6} \\
8 \times 10^{6}\end{array}$ & $\begin{array}{c}- \\
- \\
- \\
- \\
1 \times 10^{9}\end{array}$ \\
\hline $\begin{array}{l}10-30 \mathrm{~s} \\
\text { FCK we } \\
\text { Bone } \\
\text { PH KB } \\
\text { Bone } \\
\text { Ext. Dose (WD) }\end{array}$ & $\begin{array}{c}5 \times 10^{-4} \\
4 \times 10^{-3} \\
2 \times 10^{-4} \\
1 \times 10^{-3} \\
0\end{array}$ & $\begin{array}{c}1 \times 10^{-7} \\
2 \times 10^{-7} \\
1 \times 10^{-4} \\
3 \times 10^{-4} \\
0\end{array}$ & $\begin{array}{l}4 \times 10^{-4} \\
4 \times 10^{-4} \\
4 \times 10^{-3} \\
4 \times 10^{-3} \\
4 \times 10^{-4} \\
\end{array}$ & $\begin{array}{c}- \\
- \\
- \\
- \\
2 \times 10^{-2}\end{array}$ & $\begin{array}{l}9 \times 10^{-4} \\
4 \times 10^{-3} \\
4 \times 10^{-3} \\
5 \times 10^{-3} \\
2 \times 10^{-2}\end{array}$ & $1.4 \times 10^{8}$ & $\begin{array}{l}1 \times 10^{5} \\
6 \times 10^{5} \\
6 \times 10^{5} \\
7 \times 10^{5} \\
3 \times 10^{6}\end{array}$ & $\begin{array}{c}- \\
- \\
- \\
- \\
4 \times 10^{8}\end{array}$ \\
\hline $\begin{array}{l}30=50 \mathrm{~s} \\
\text { FOK WB } \\
\text { Bone } \\
\text { PH WB } \\
\text { Done } \\
\text { Ext. Dose (WB) }\end{array}$ & $\begin{array}{c}9 \times 10^{-4} \\
8 \times 10^{-3} \\
3 \times 10^{-4} \\
3 \times 10^{-3} \\
0 \\
\end{array}$ & $\begin{array}{c}2 \times 10^{-7} \\
5 \times 10^{-7} \\
3 \times 10^{-4} \\
6 \times 10^{-4} \\
.\end{array}$ & $\begin{array}{l}8 \times 10^{-4} \\
8 \times 10^{-4} \\
7 \times 10^{-3} \\
7 \times 10^{-3} \\
9 \times 10^{-4}\end{array}$ & $\begin{array}{c}- \\
- \\
5 \times 10^{-2} \\
\end{array}$ & $\begin{array}{l}2 \times 10^{-3} \\
9 \times 10^{-3} \\
8 \times 10^{-3} \\
1 \times 10^{-2} \\
5 \times 10^{-2}\end{array}$ & $5.3 \times 10^{7}$ & $\begin{array}{l}1 \times 10^{5} \\
5 \times 10^{5} \\
4 \times 10^{5} \\
5 \times 10^{5} \\
3 \times 10^{6}\end{array}$ & $\begin{array}{c}- \\
- \\
- \\
- \\
2 \times 10^{8}\end{array}$ \\
\hline $\begin{array}{l}\text { 80-70 s } \\
\text { FCM WB } \\
\text { Bone } \\
\text { PH WB } \\
\text { Bone } \\
\text { Ext. Dose (WB) } \\
\end{array}$ & $\begin{array}{c}7 \times 10^{-4} \\
5 \times 10^{-3} \\
2 \times 10^{-4} \\
2 \times 10^{-3} \\
0\end{array}$ & $\begin{array}{c}2 \times 10^{-7} \\
3 \times 10^{-7} \\
2 \times 10^{-4} \\
5 \times 10^{-4} \\
\end{array}$ & $\begin{array}{l}6 \times 10^{-4} \\
6 \times 10^{-4} \\
5 \times 10^{-3} \\
5 \times 10^{-3} \\
6 \times 10^{-4} \\
\end{array}$ & $\begin{array}{c}- \\
- \\
- \\
- \\
3 \times 10^{-2} \\
\end{array}$ & $\begin{array}{l}1 \times 10^{-3} \\
6 \times 10^{-3} \\
5 \times 10^{-3} \\
8 \times 10^{-3} \\
3 \times 10^{-2}\end{array}$ & C & $\begin{array}{l}- \\
- \\
. \\
.\end{array}$ & $\begin{array}{l}- \\
- \\
- \\
-\end{array}$ \\
\hline $\begin{array}{l}70 \text { - } 90 \mathrm{~s} \\
\text { FCM WB } \\
\text { Bone } \\
\text { PH NO } \\
\text { Bone } \\
\text { Exe. Dose (WB) }\end{array}$ & $\begin{array}{c}1 \times 10^{-4} \\
1 \times 10^{-3} \\
4 \times 10^{-5} \\
4 \times 10^{-4} \\
0\end{array}$ & $\begin{array}{c}0 \\
3 \times 10^{-5} \\
7 \times 10^{-5} \\
0\end{array}$ & $\begin{array}{l}1 \times 10^{-4} \\
1 \times 10^{-4} \\
9 \times 10^{-4} \\
9 \times 10^{-4} \\
1 \times 10^{-4}\end{array}$ & $\begin{array}{c}- \\
- \\
- \\
- \\
6 \times 10^{-3}\end{array}$ & $\begin{array}{l}2 \times 10^{-4} \\
1 \times 10^{-3} \\
1 \times 10^{-3} \\
1 \times 10^{-3} \\
6 \times 10^{-3}\end{array}$ & c & $\begin{array}{l}- \\
- \\
. \\
-\end{array}$ & $\begin{array}{l}- \\
- \\
- \\
-\end{array}$ \\
\hline & ${ }^{\circ}$ & & & \multicolumn{2}{|c|}{$\begin{array}{l}\text { Norld lotele } \\
\text { Unit }\end{array}$} & $\begin{array}{l}3.9 \times 10^{9} \\
\text { People }\end{array}$ & $\begin{array}{c}2 \times 10^{8} \\
\text { (Persion-Rem) }\end{array}$ & $\begin{array}{c}1 \times 10^{10} \\
\text { (Person-Ram) }\end{array}$ \\
\hline
\end{tabular}

\footnotetext{
Dose $<10^{-7}$ Rem
Source -1975 Information Please Almanec

Assunics $0.1 \mathrm{Ren} / \mathrm{y}$ in each latitude band

Doses re to whole body oniy

Mot calculated

FCM - Forags-cow-rillk patliway

PH - Posture-nzat pathway

WB - Mliole Body
} 
FIGURE CAPTIONS.

Figure 1. The average cloud center trajectory for the $100 \mathrm{kt}$ lower troposphere air burst near Johnston Island.

Figure 2. The average cloud center trajectory for the $500 \mathrm{kt}$ surface burst near Johnston Island.

Figure 3. The average cloud center trajectories for the $100 \mathrm{kt}$ lower troposphere air burst near Baker Island.

Figure 4. The close-in deposition pattern for the 1-Mt surface event on Kingman Reef. By means of the conversion factors listed in Table 3. The contours may be transformed into actual deposition values.

Figure 5. The close-in deposition pattern for the $500 \mathrm{kt}$ surface event near Johnston Island. By means of the conversion factors listed in Table 3, the contours may be transformed into actual deposition values. 


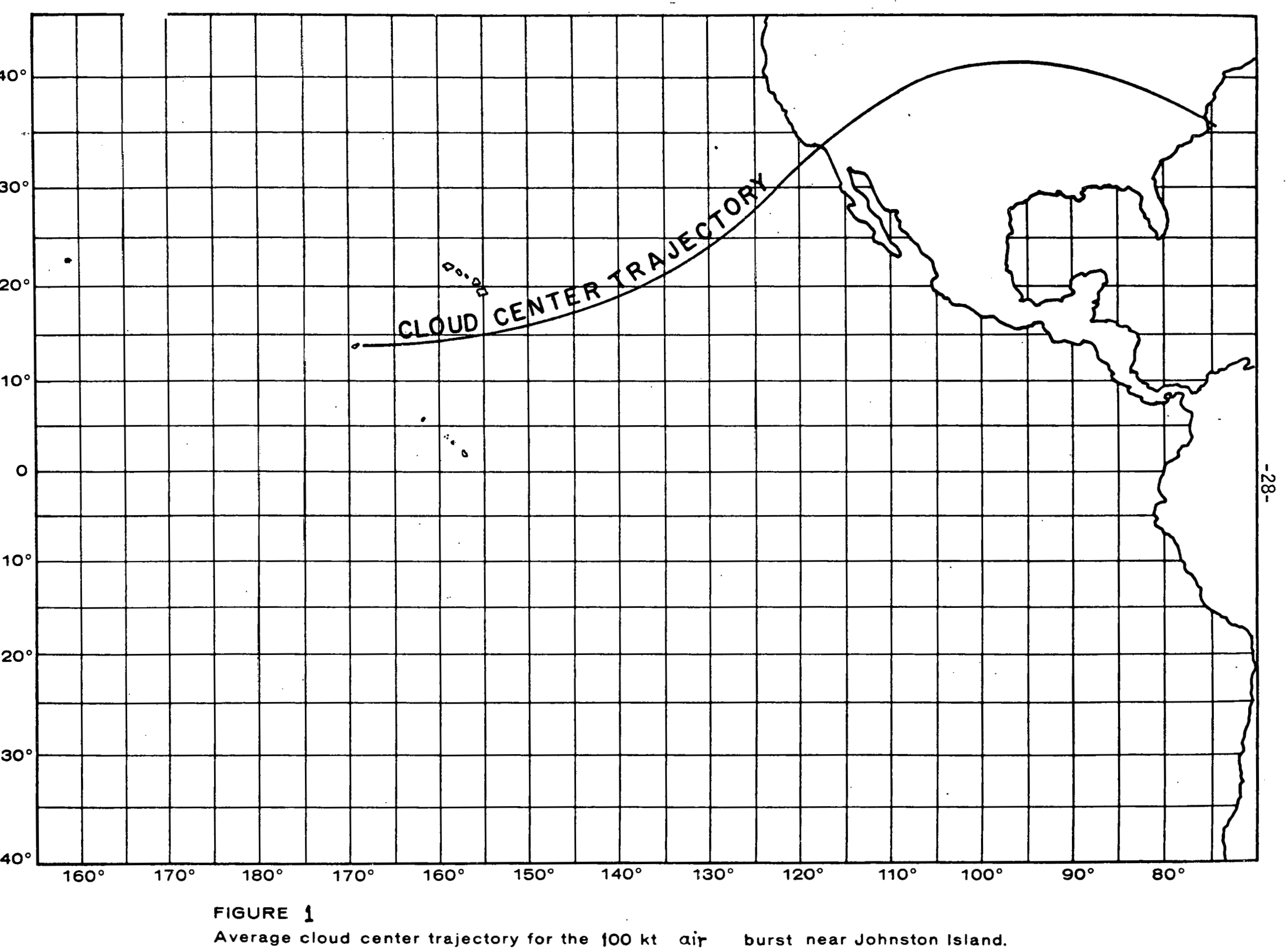




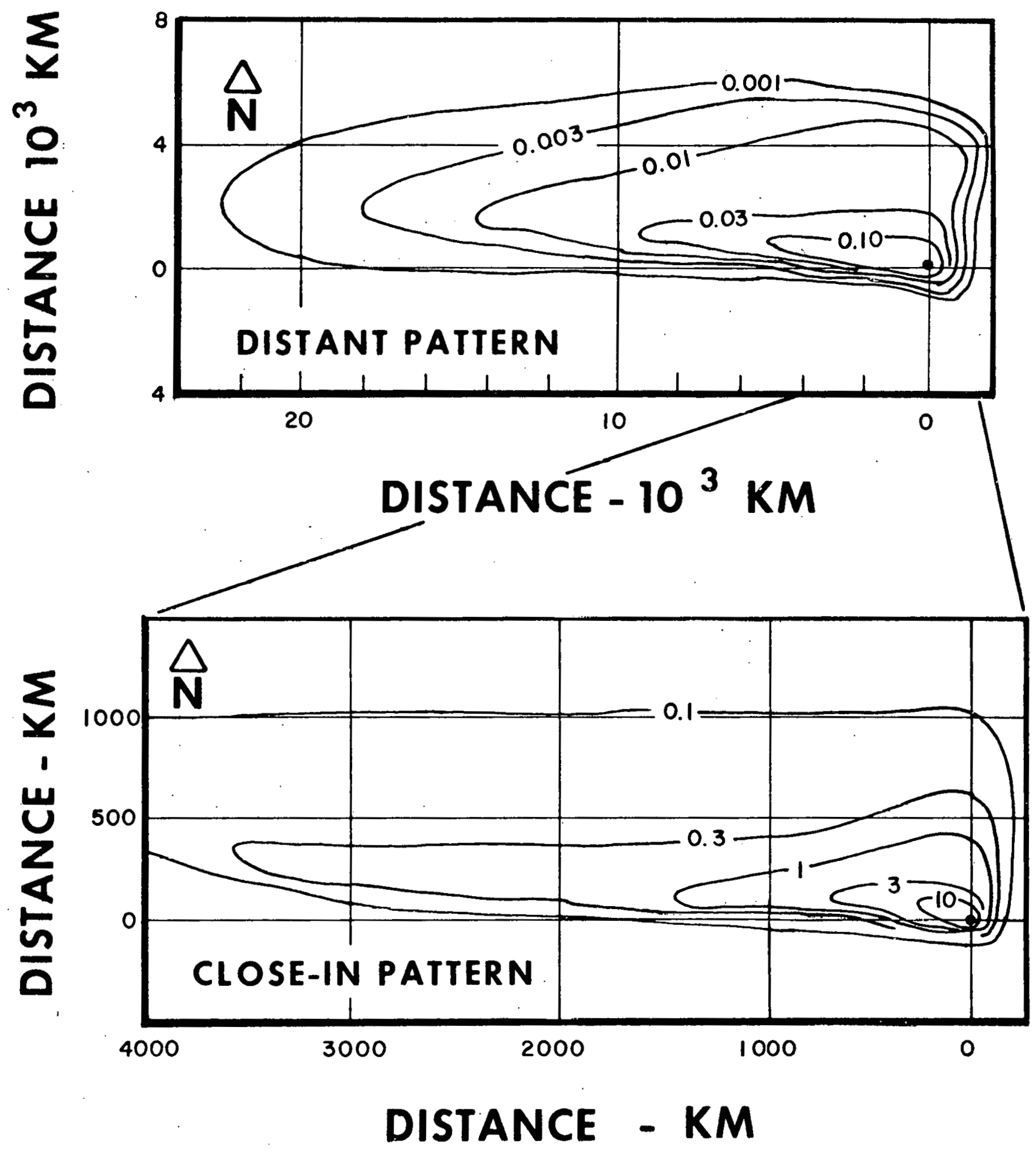

FIGURE 4

Distribution of fallout in relative units see Table 3 I for $1.0 \mathrm{Mt}$. surface burst at Area K. 


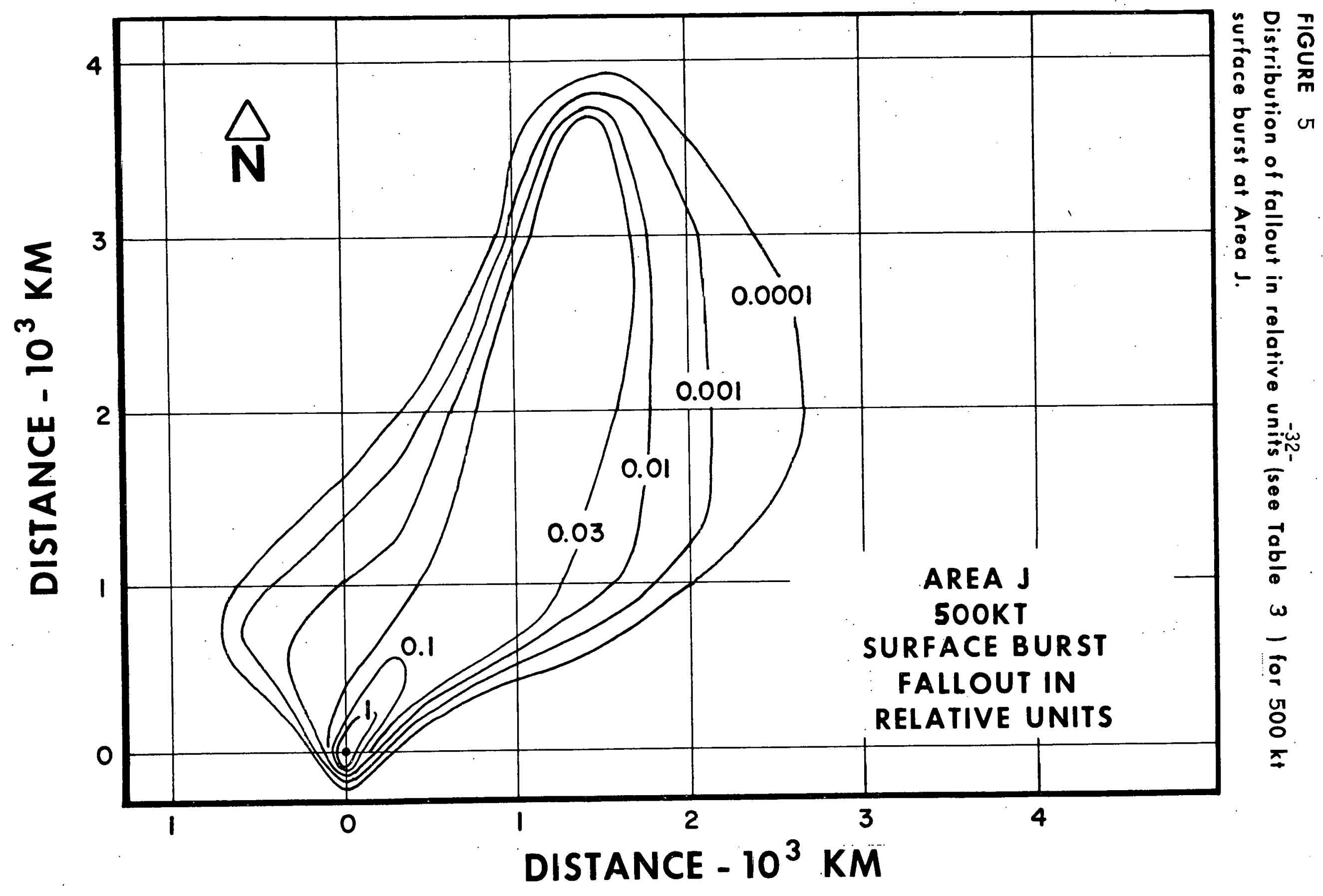




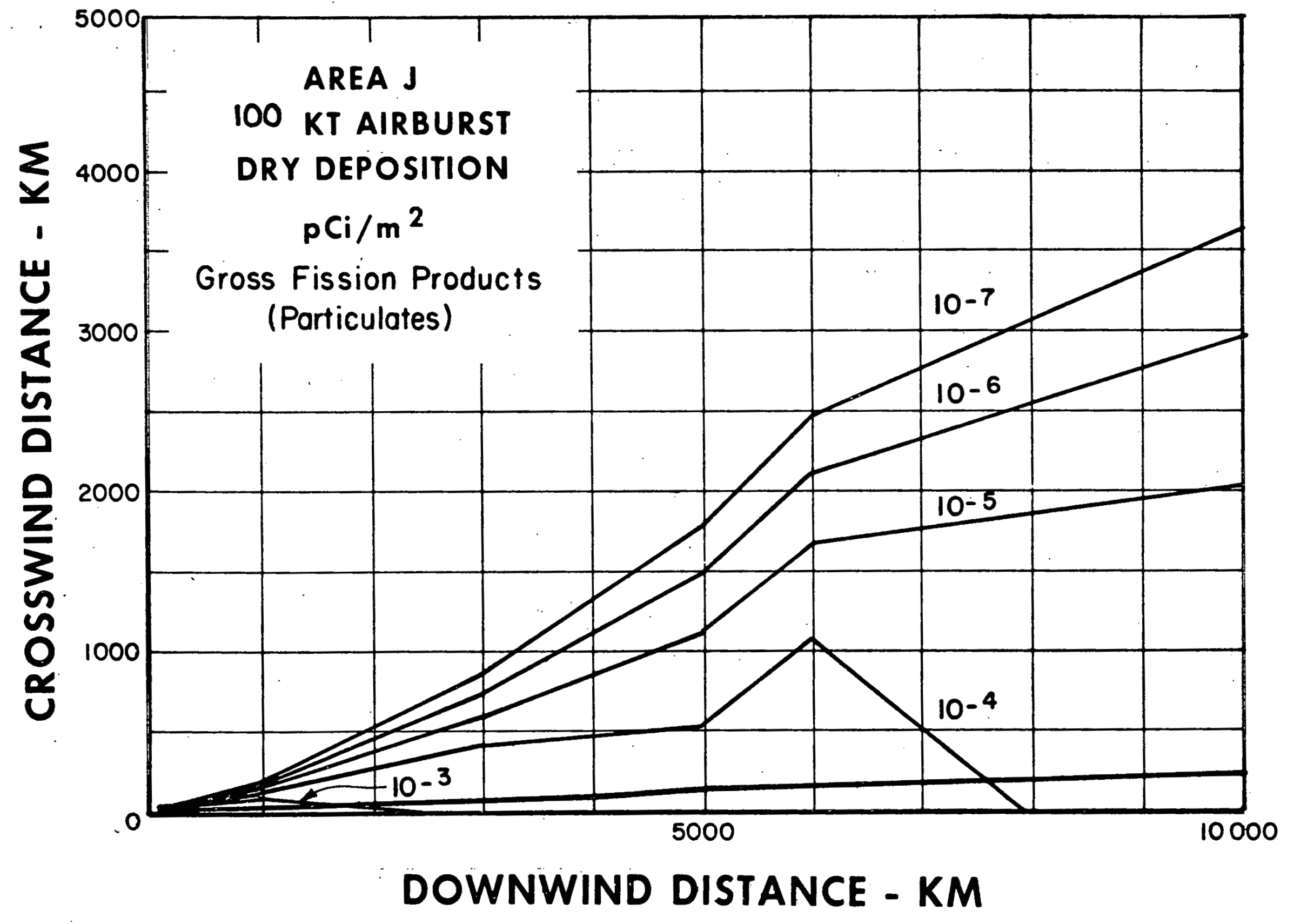




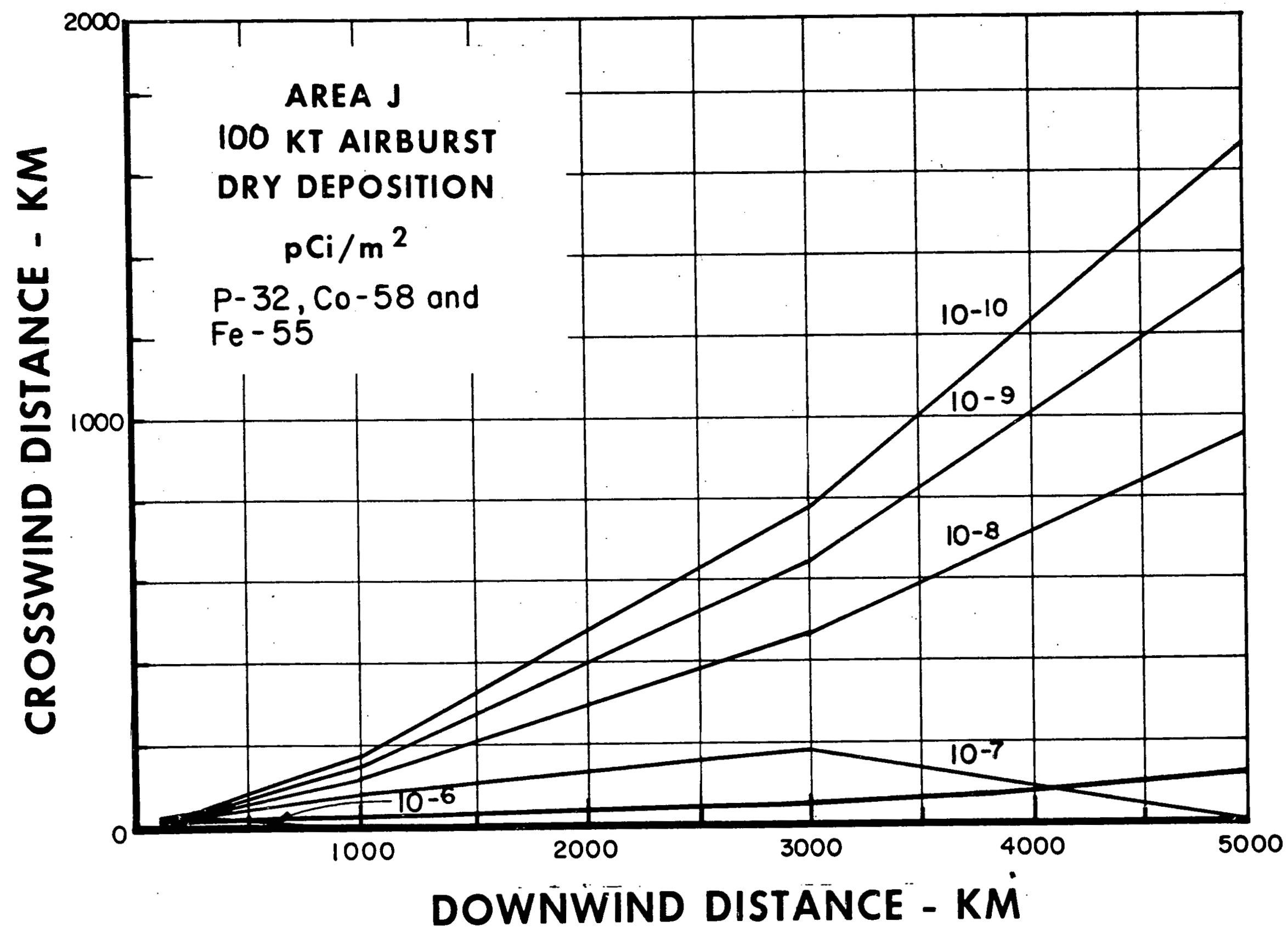




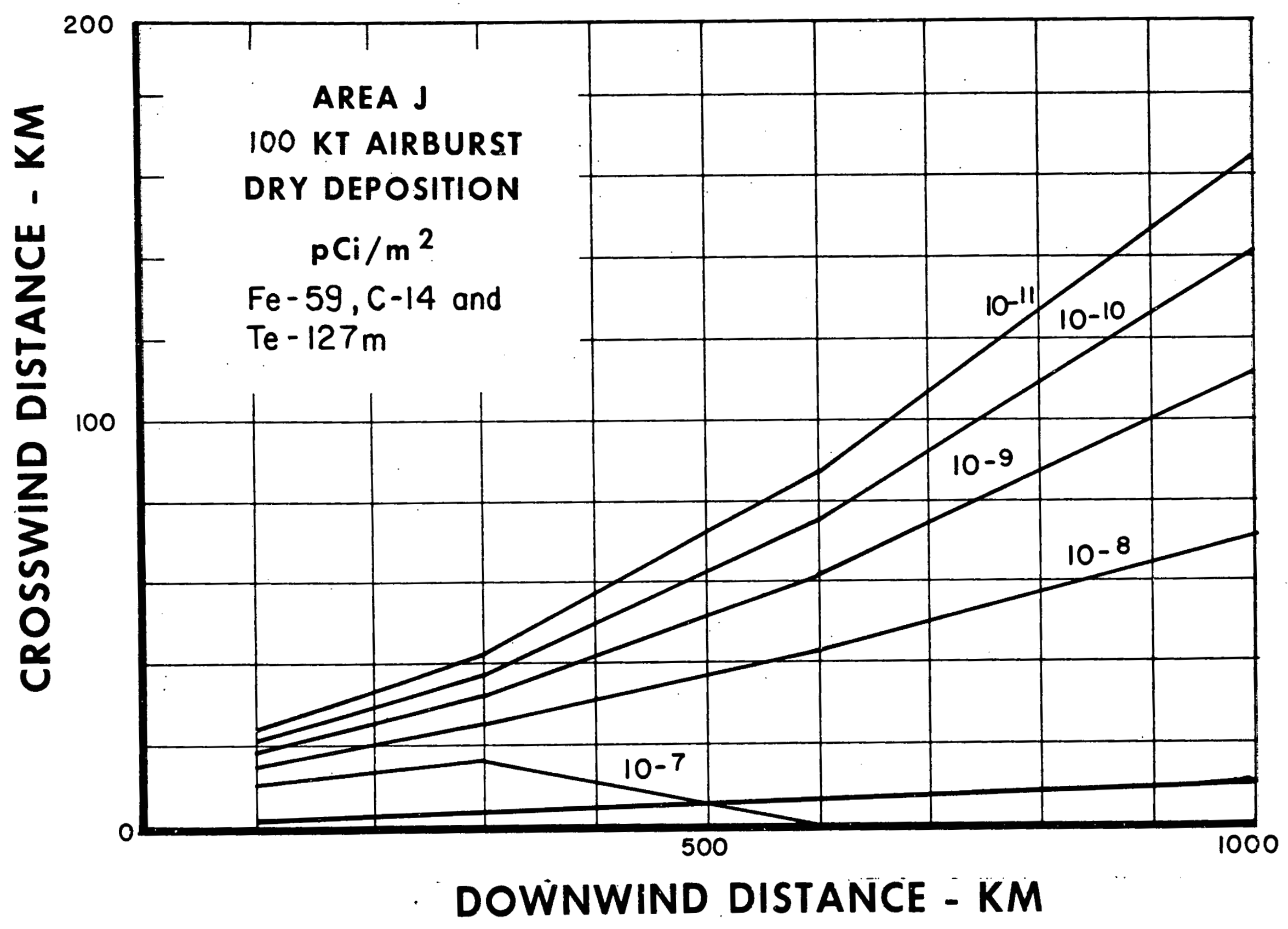




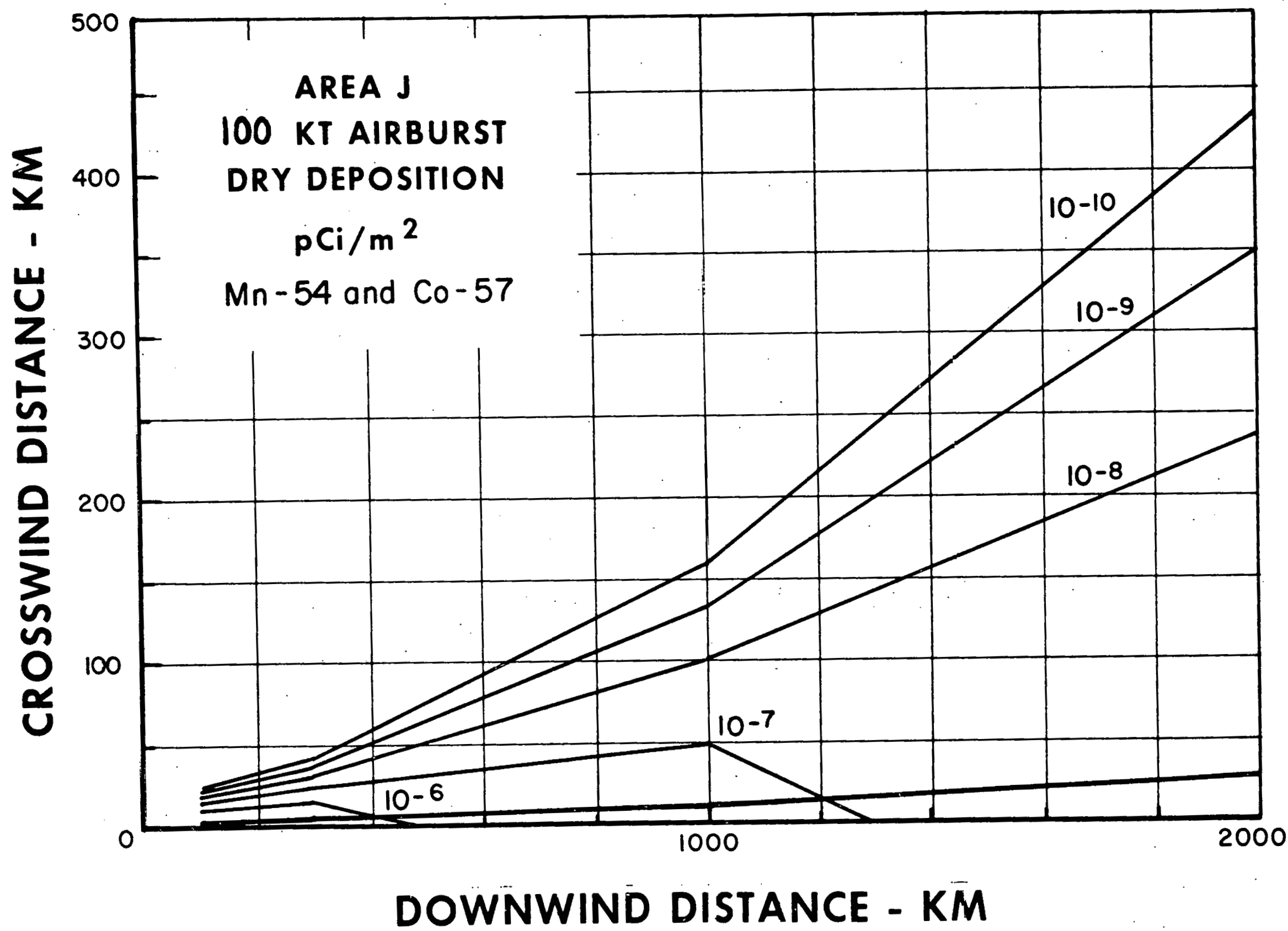




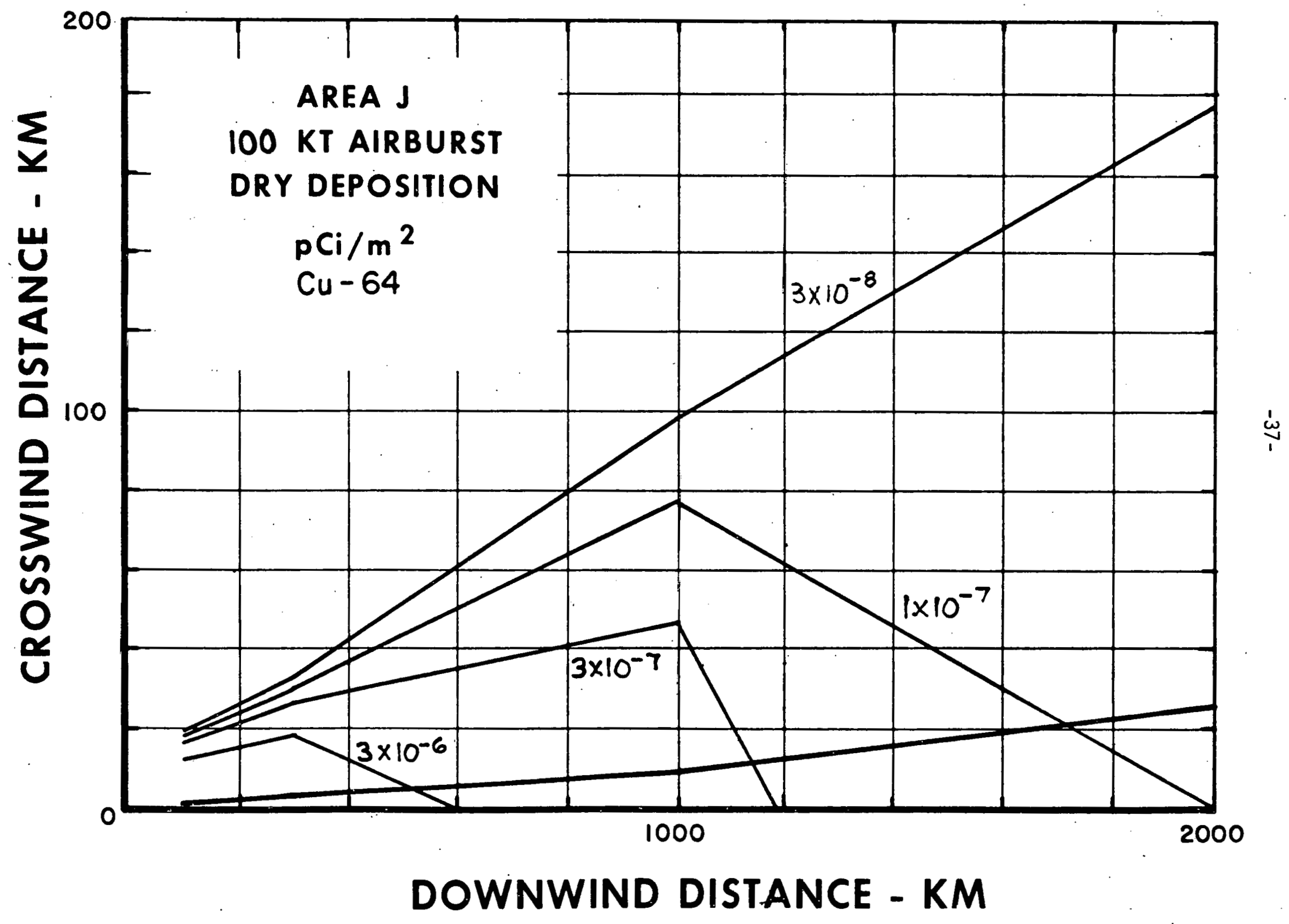




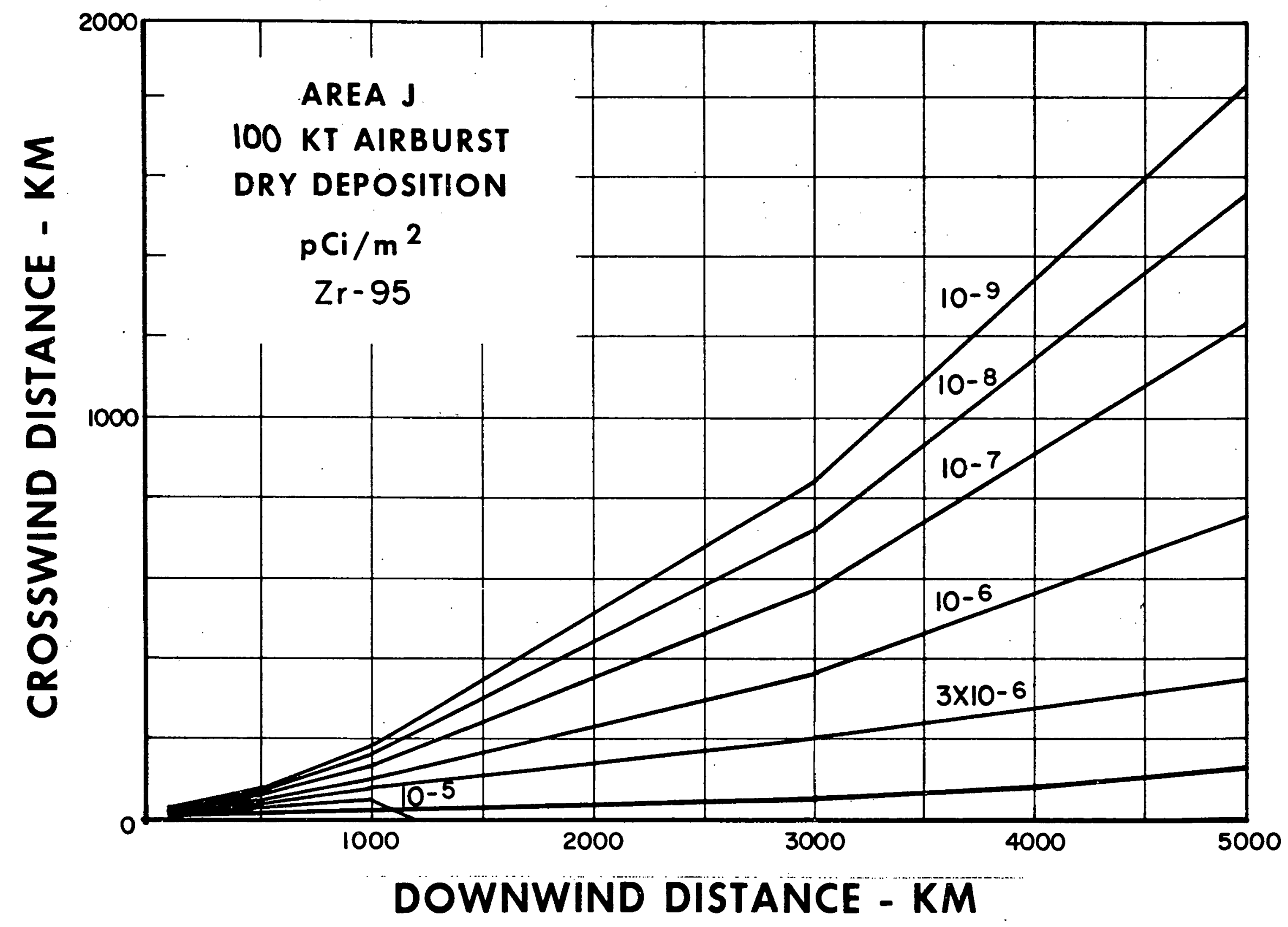




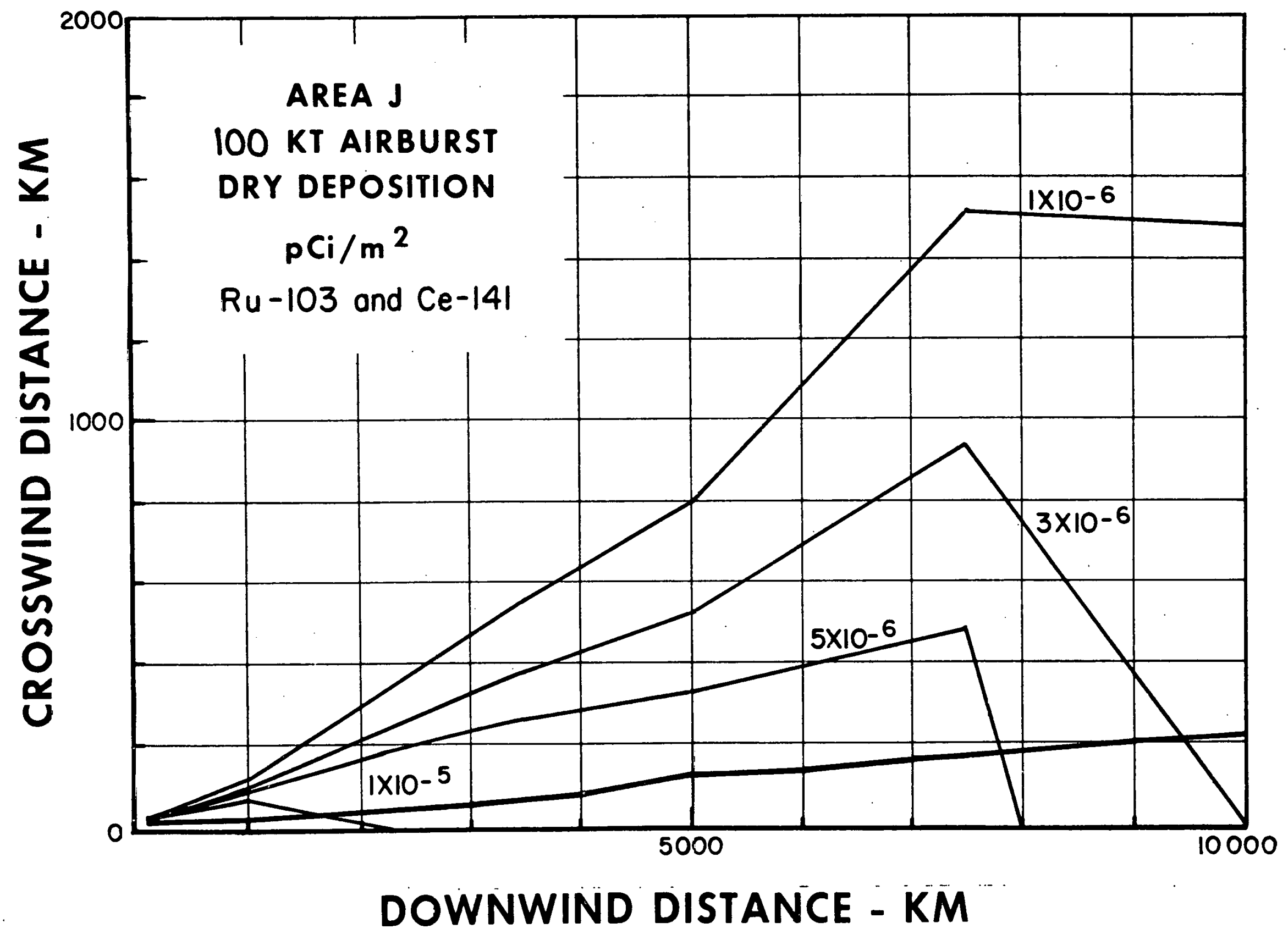




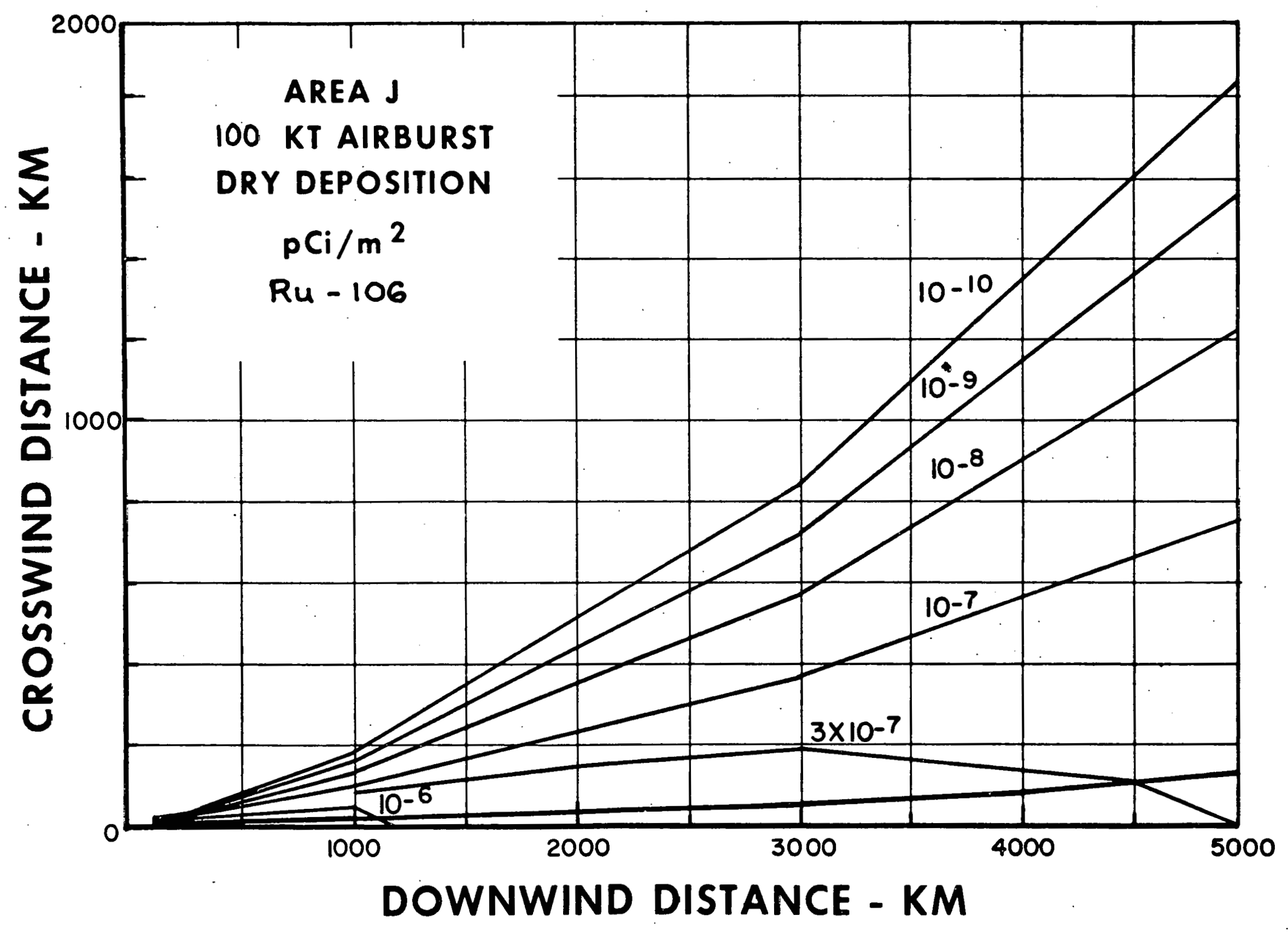




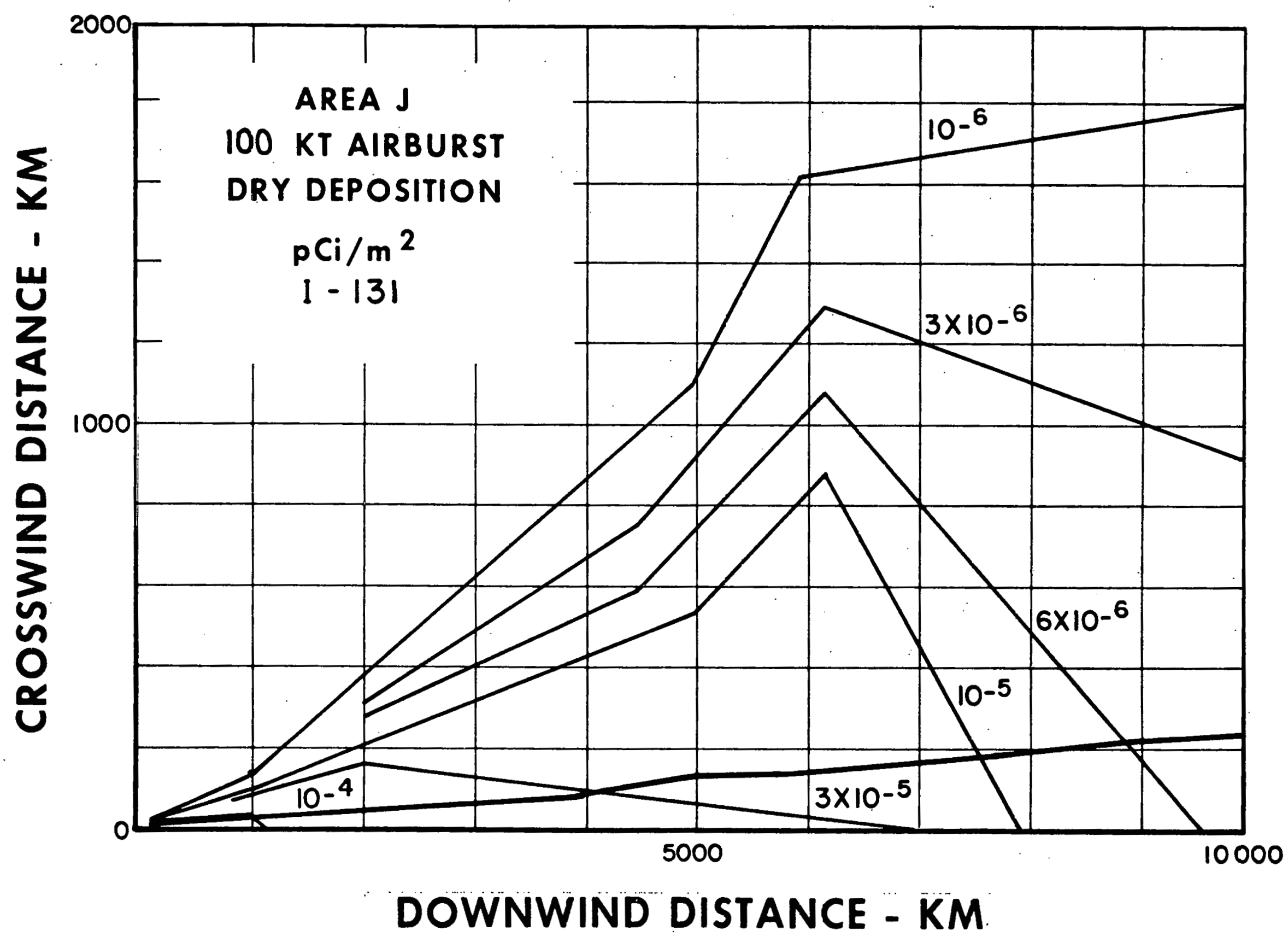




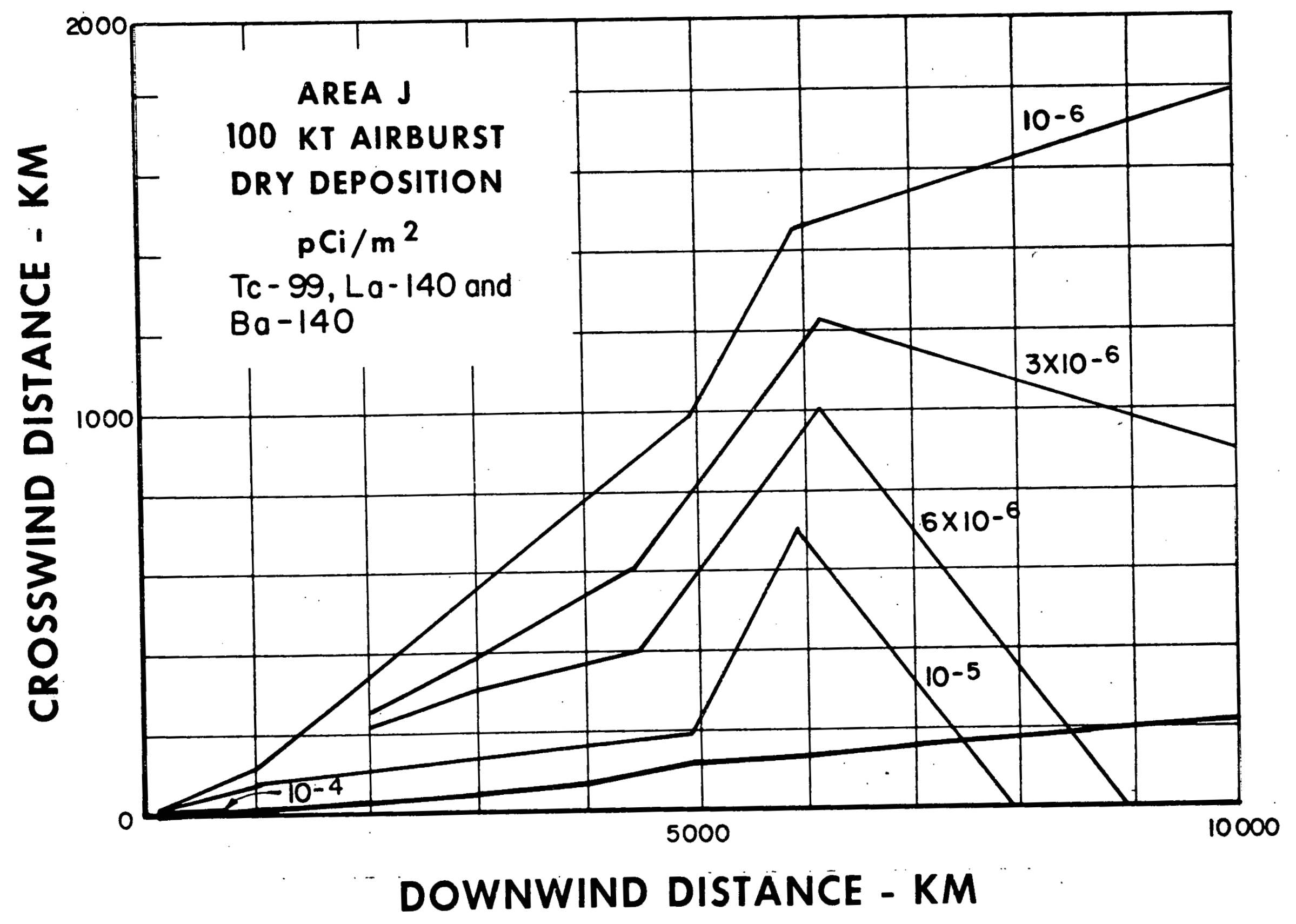




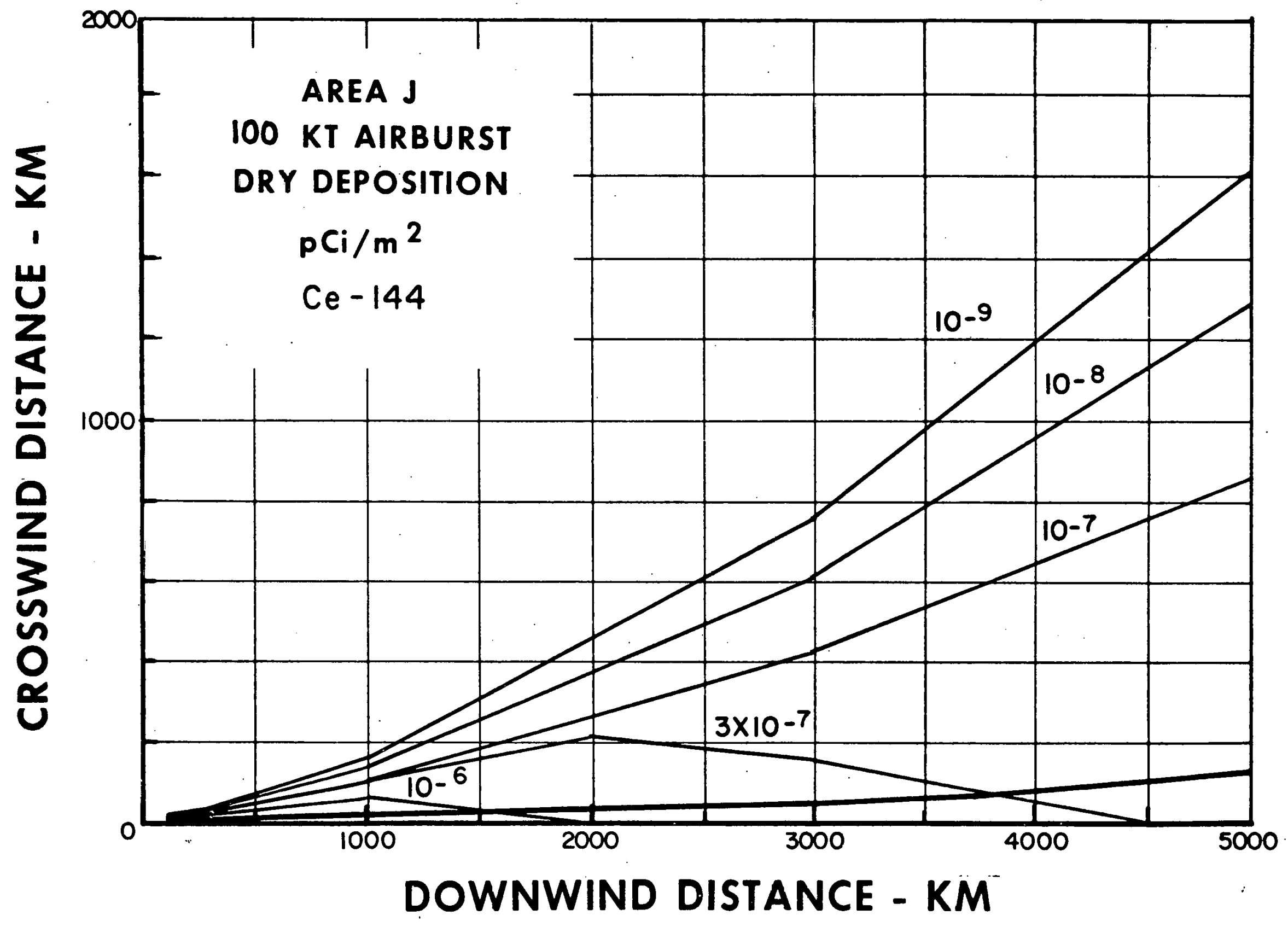




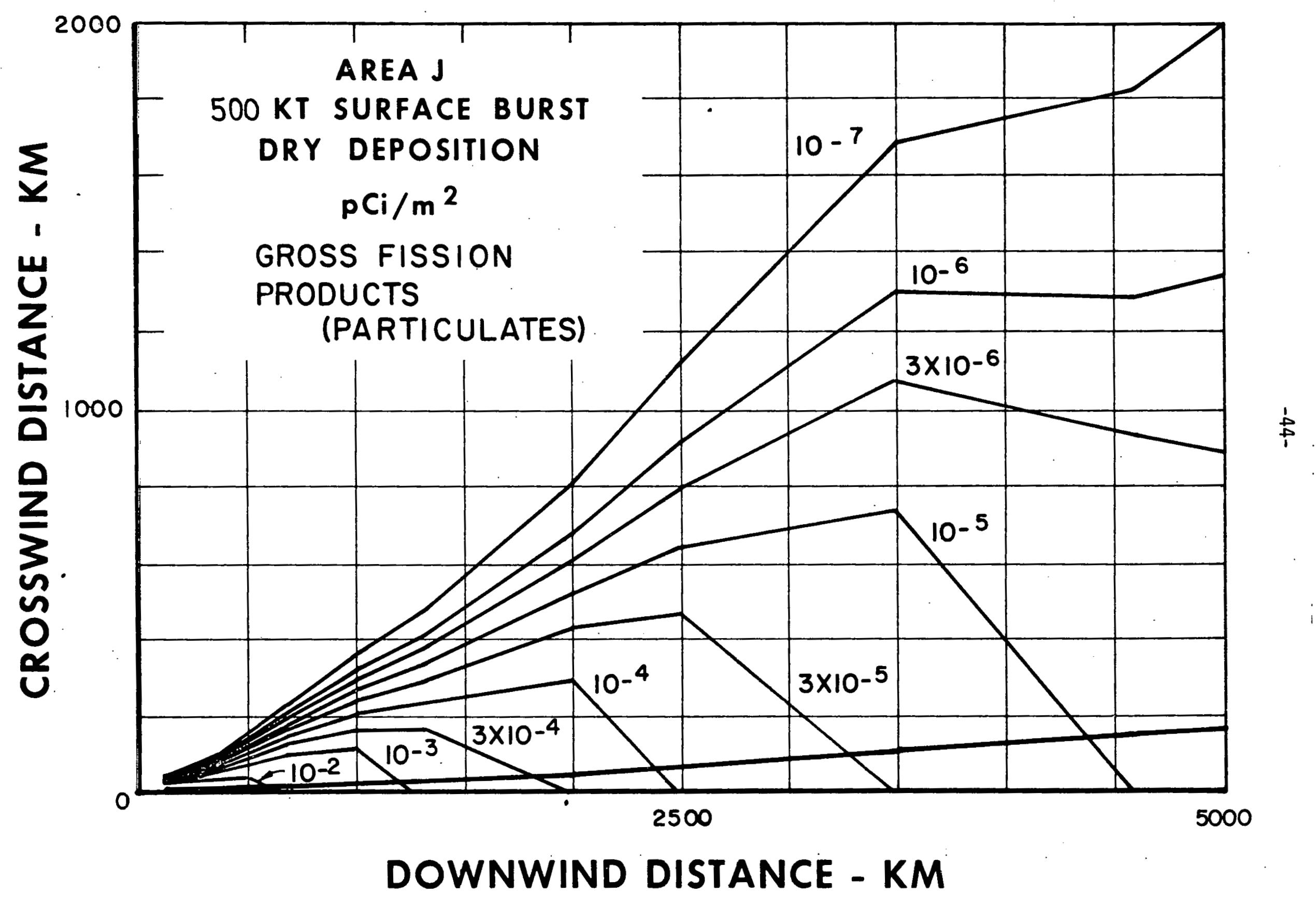




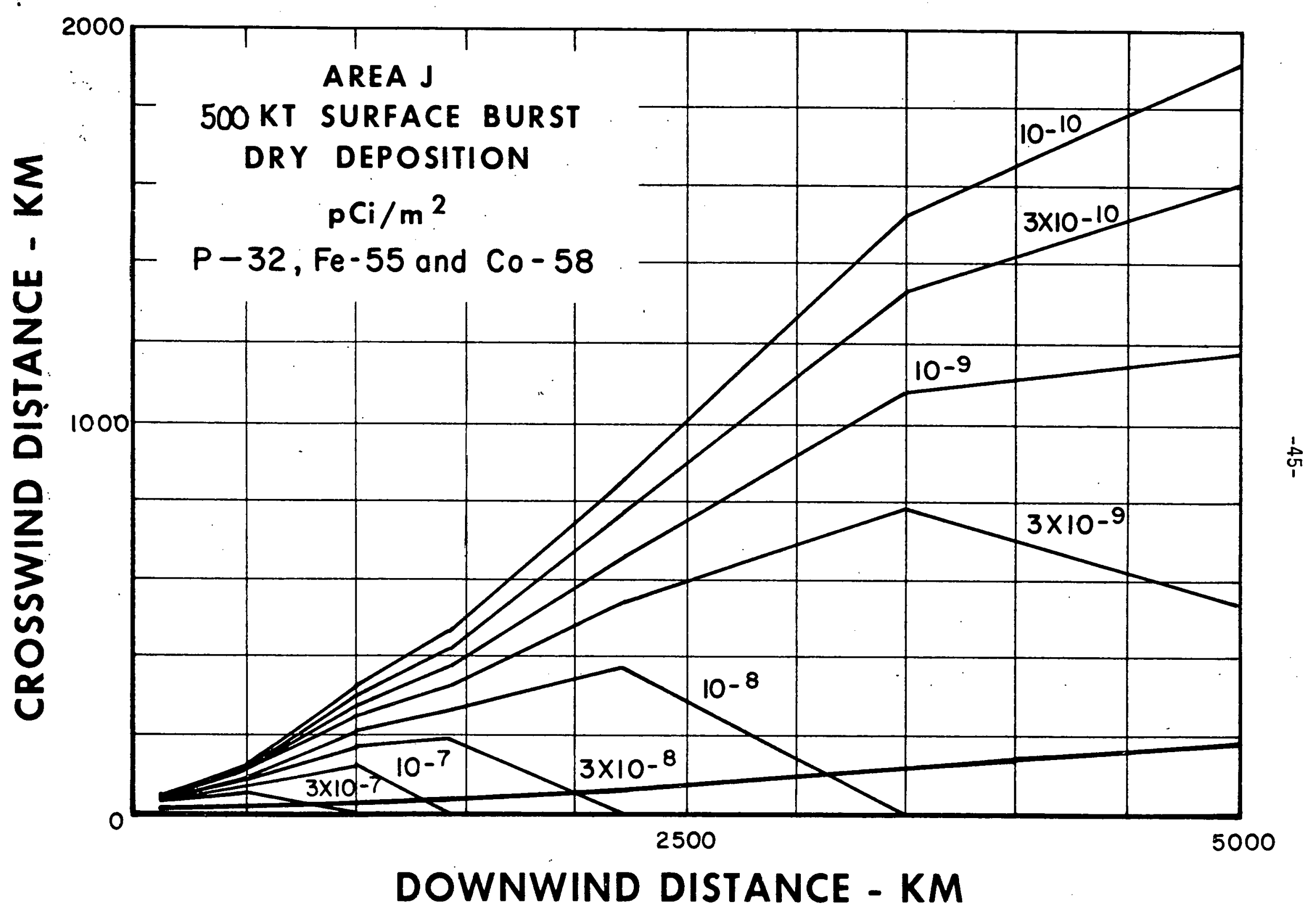




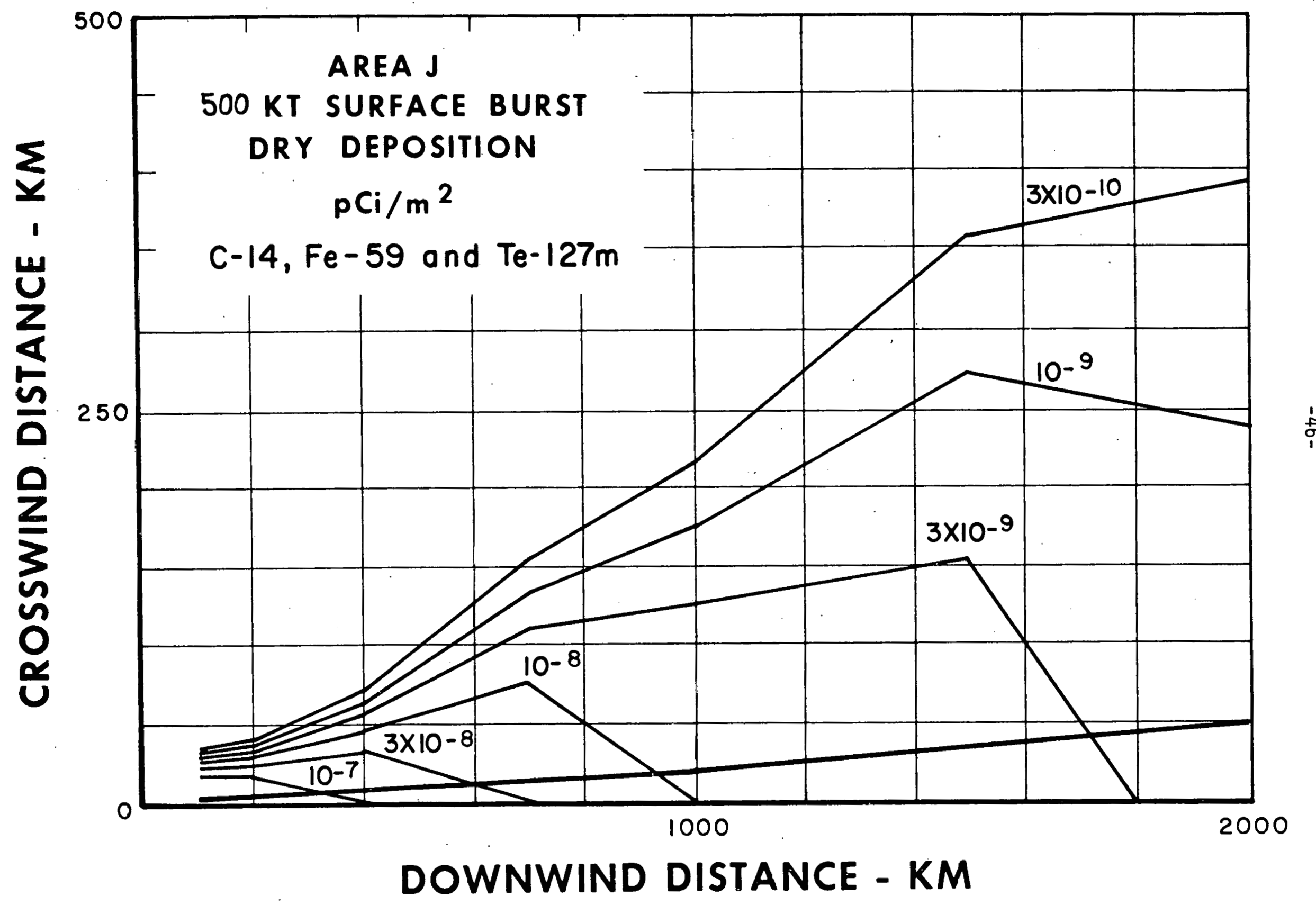




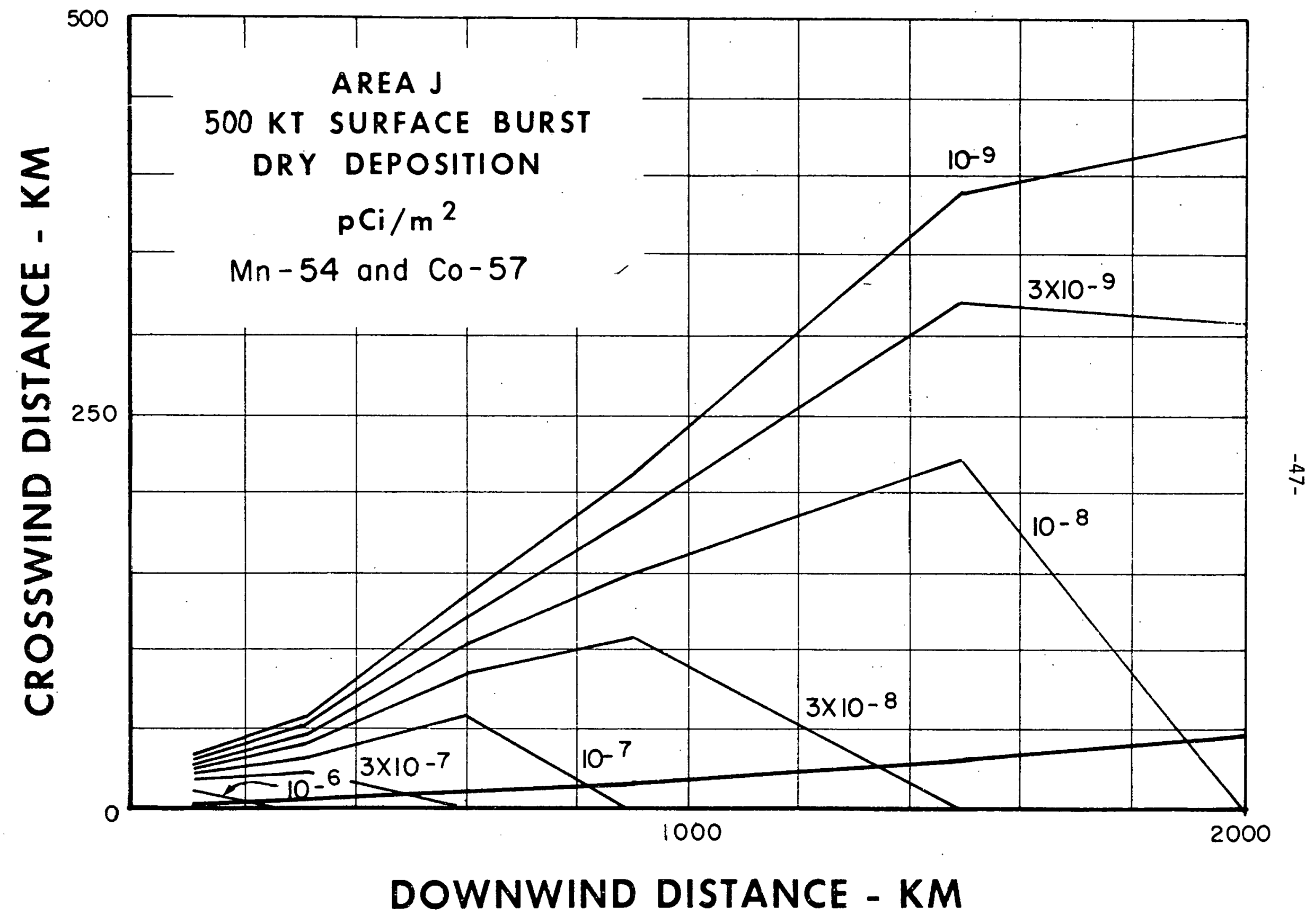




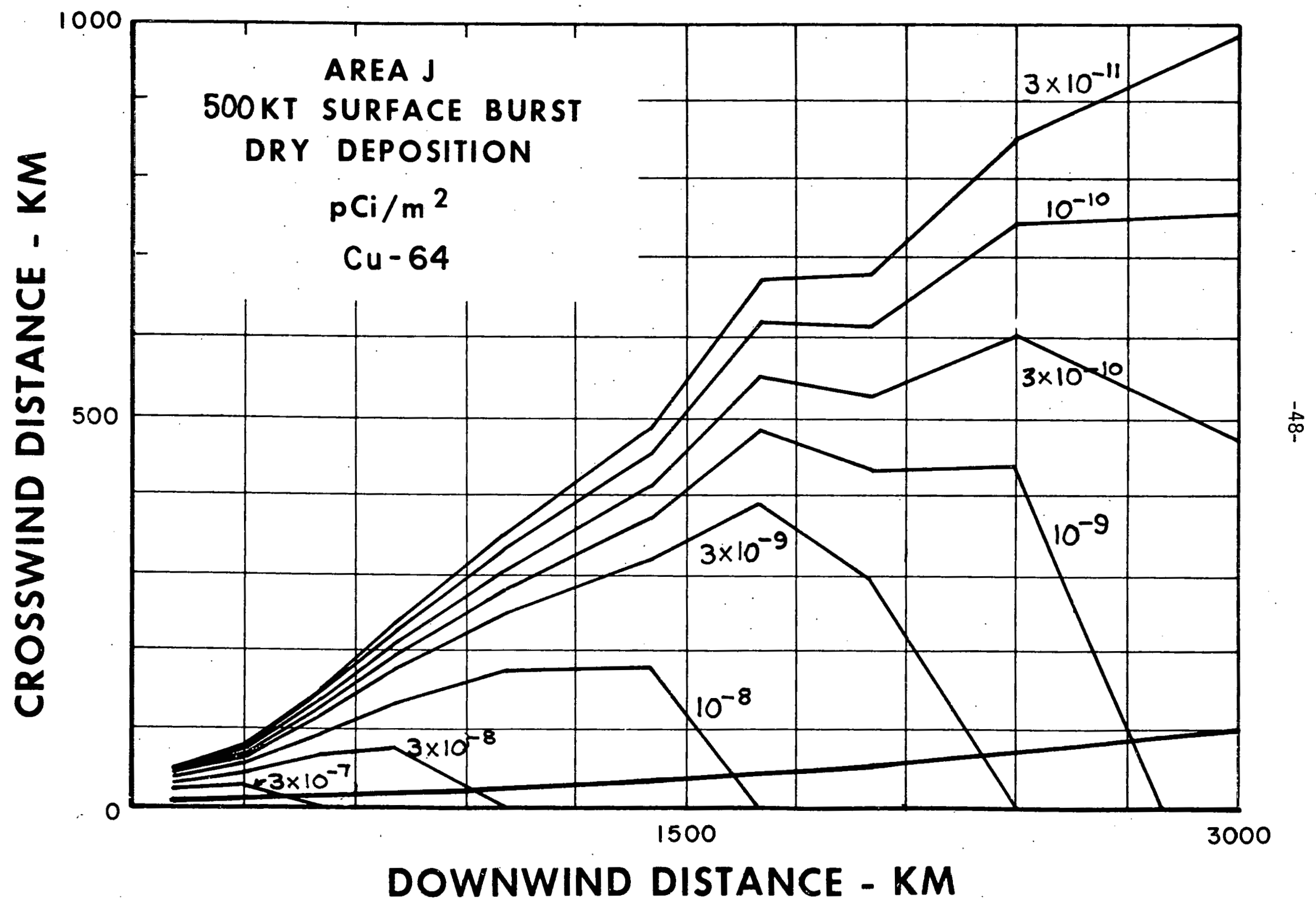




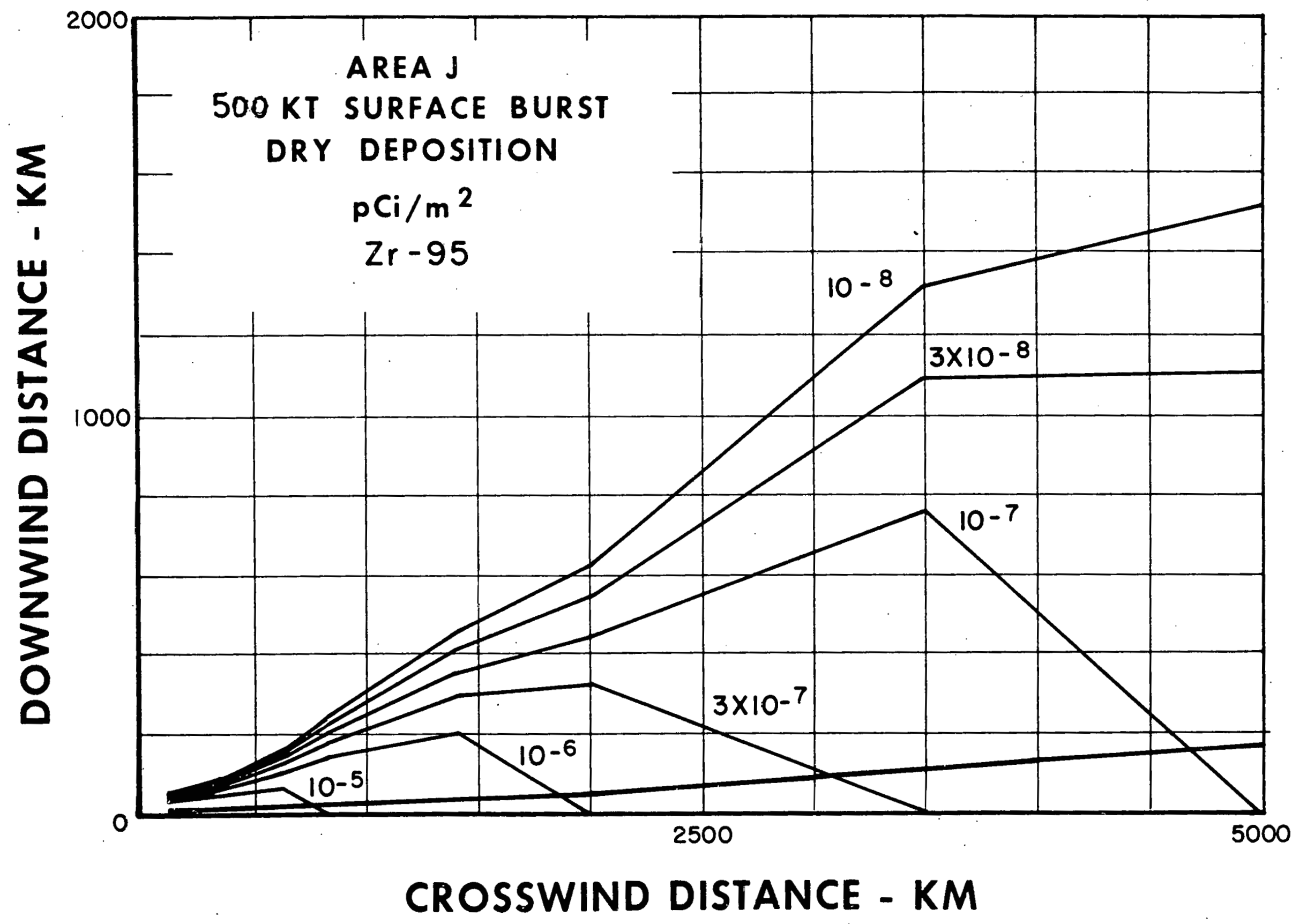




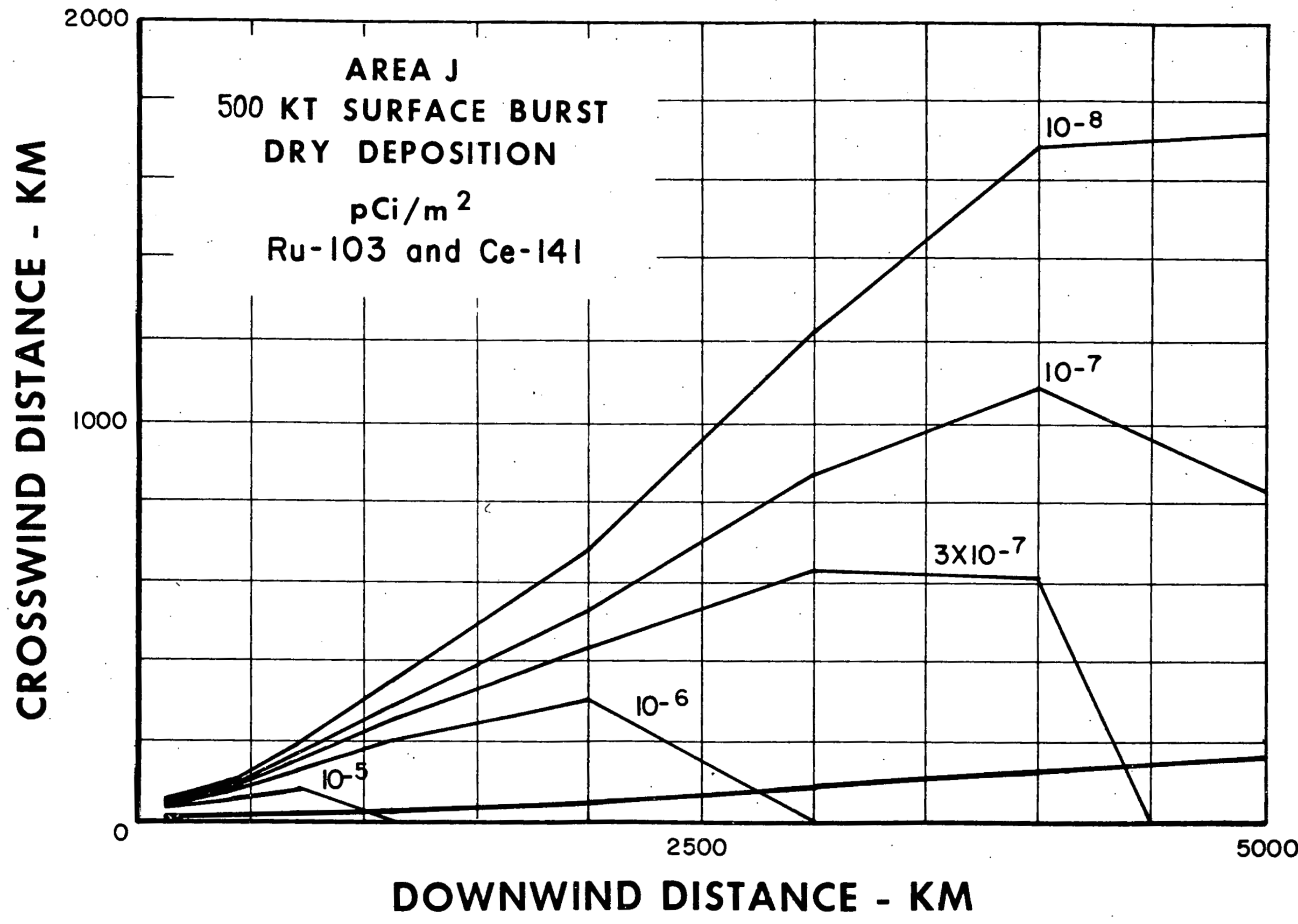




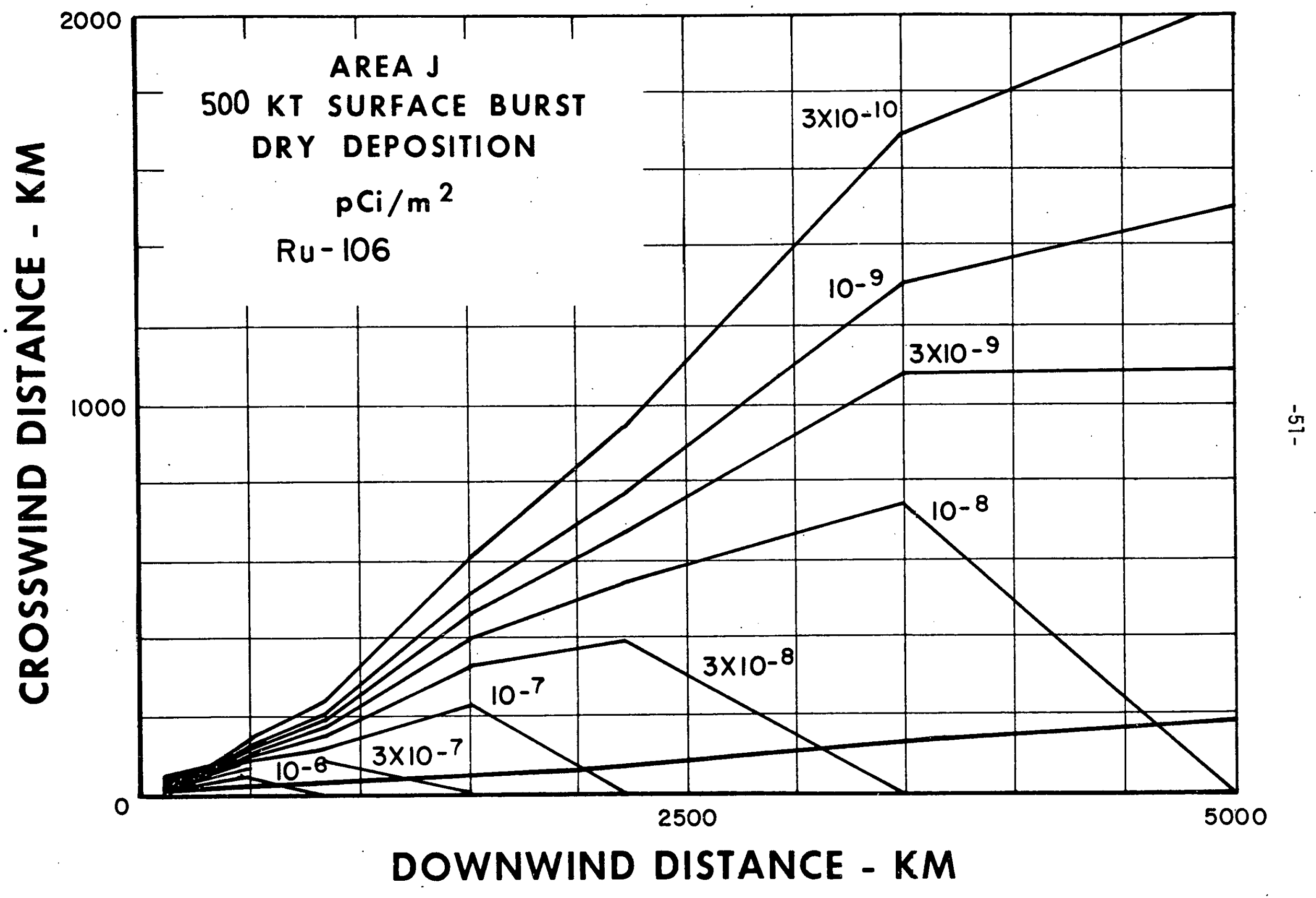




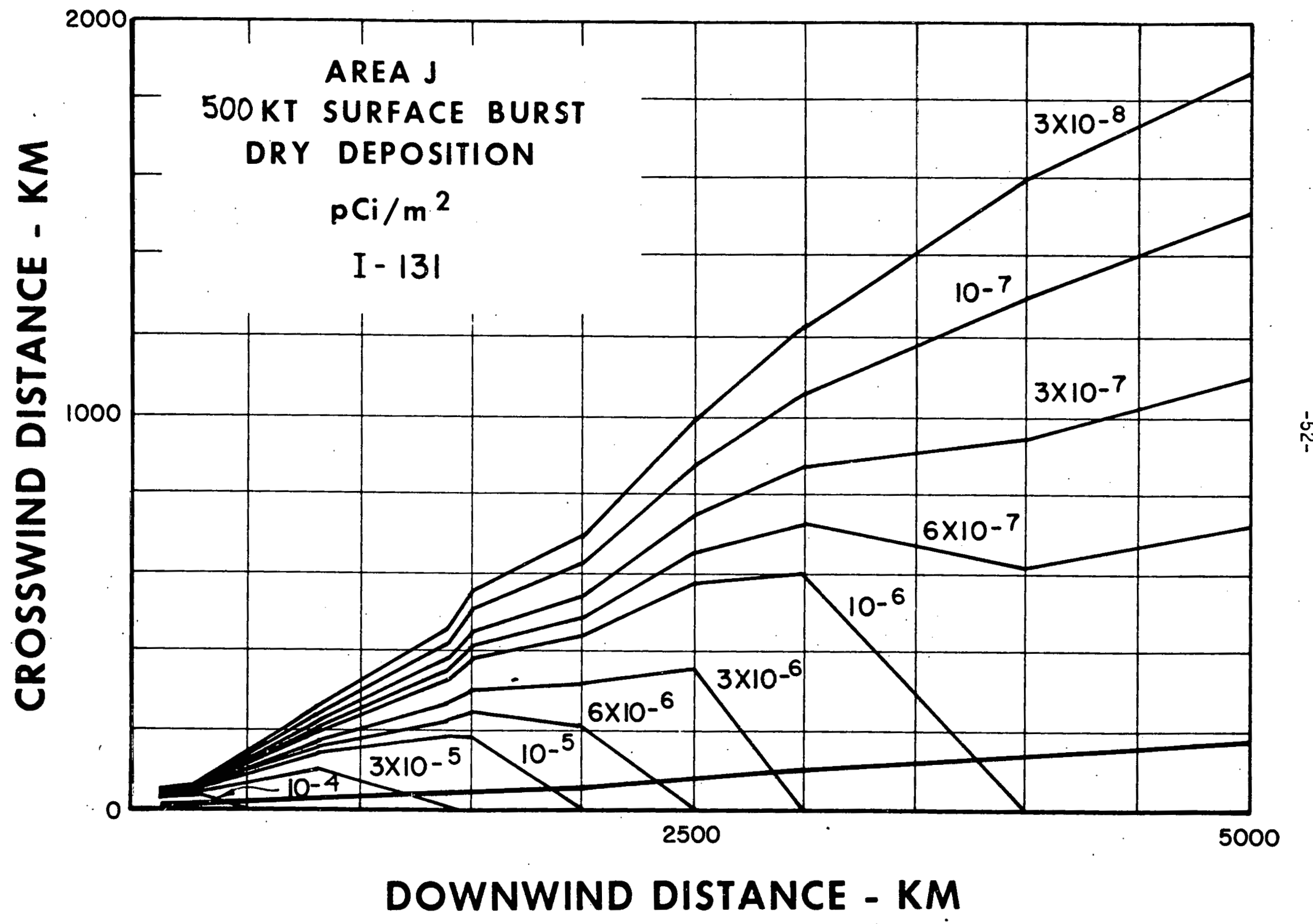




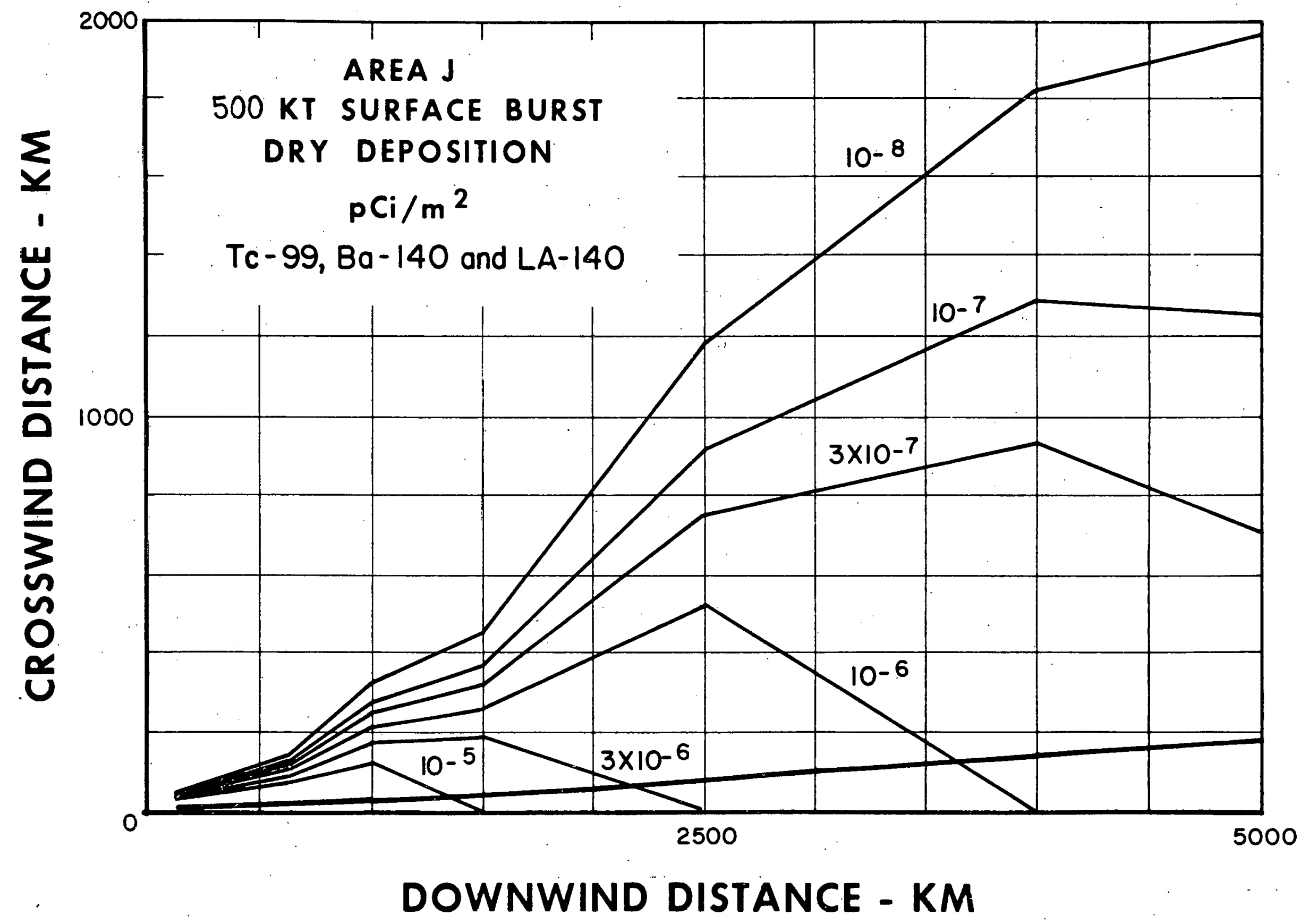




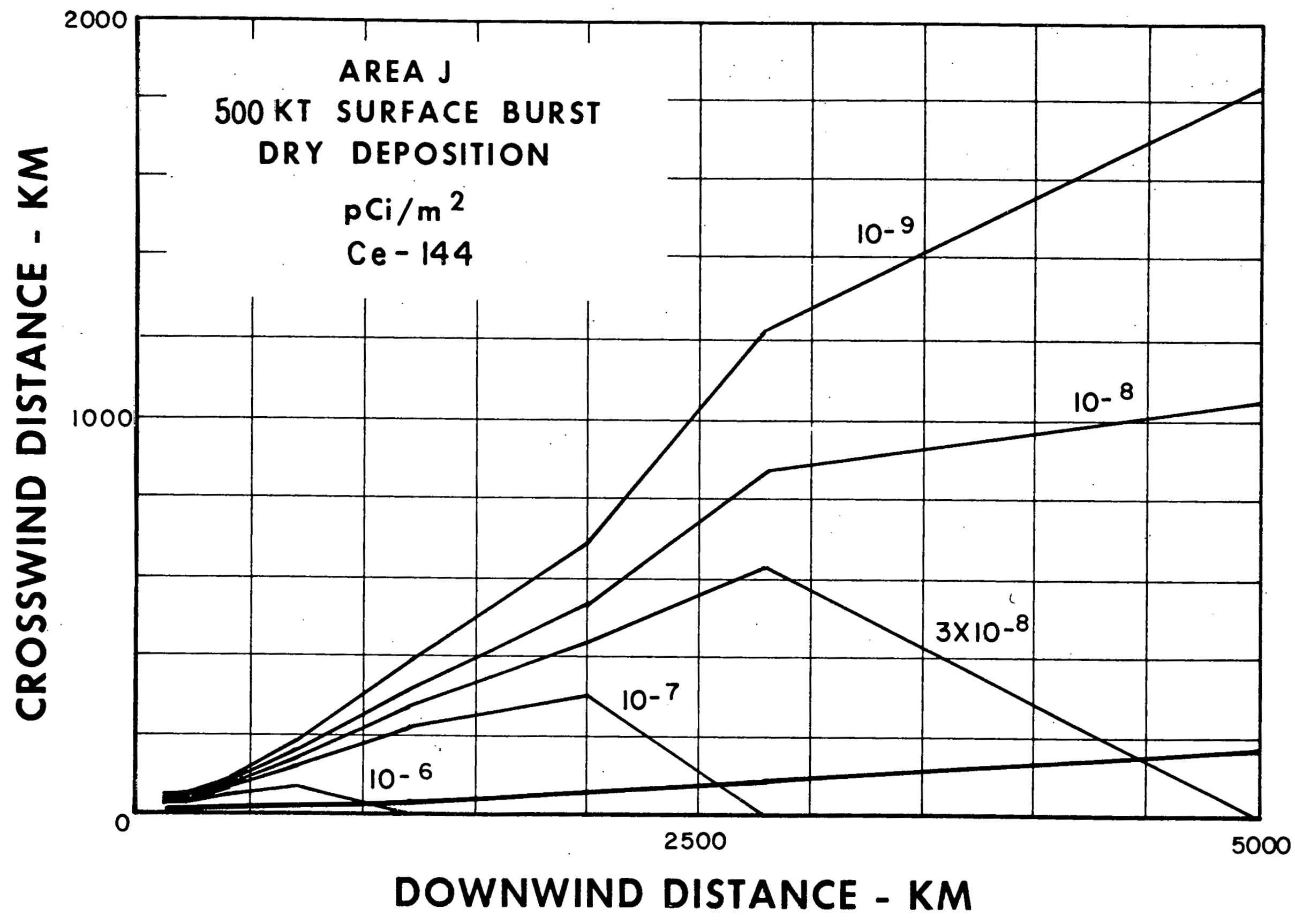




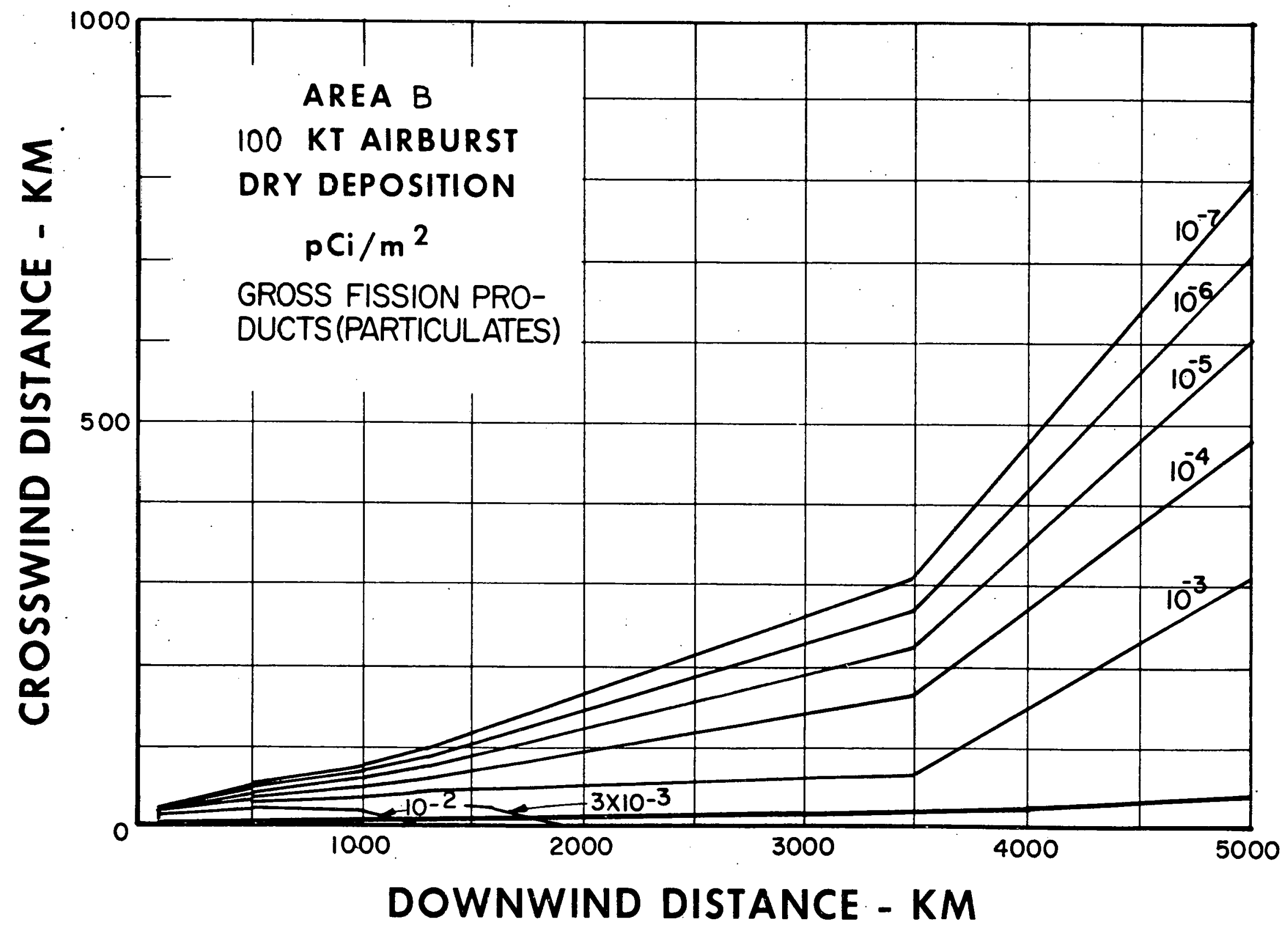




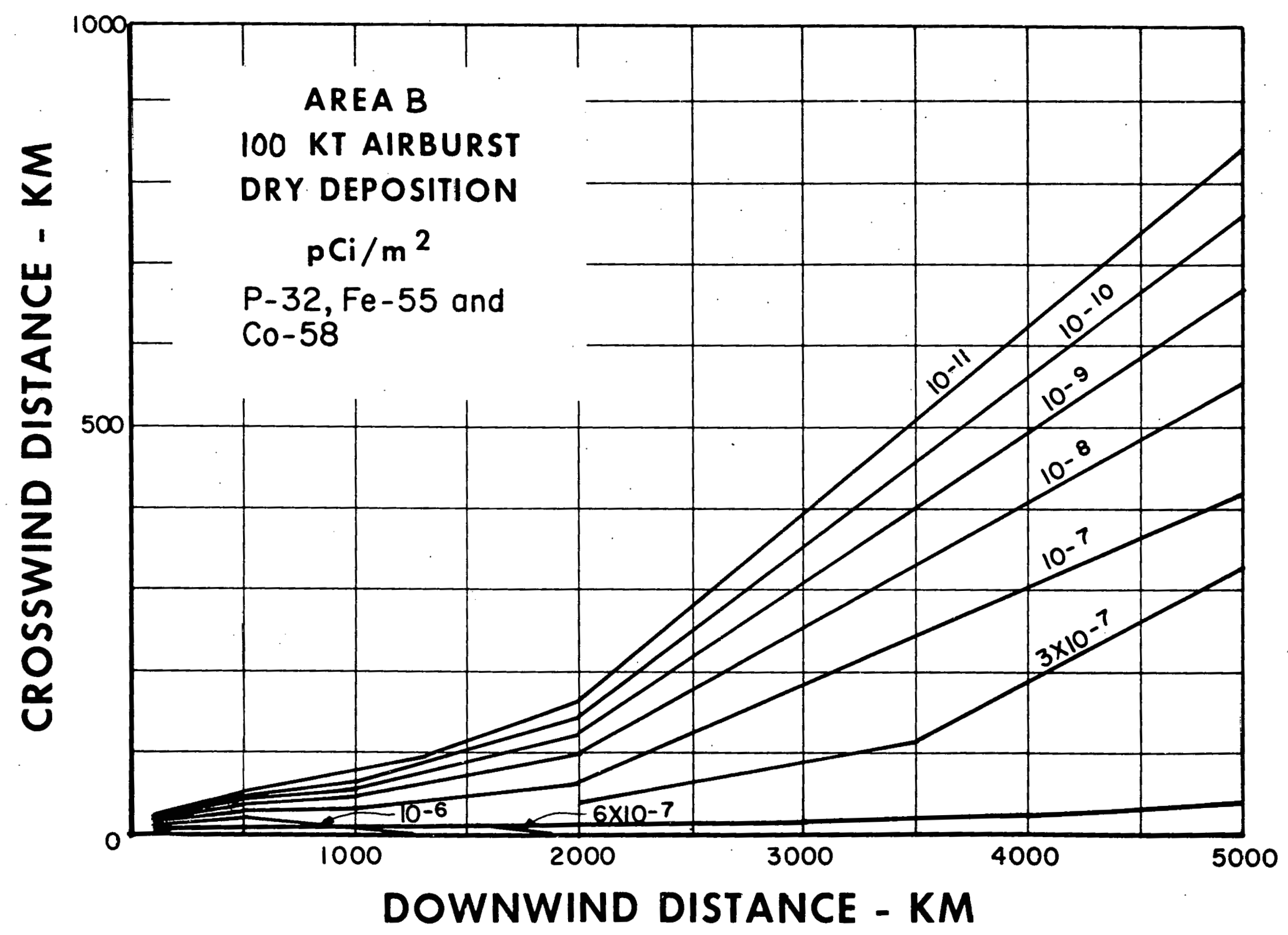




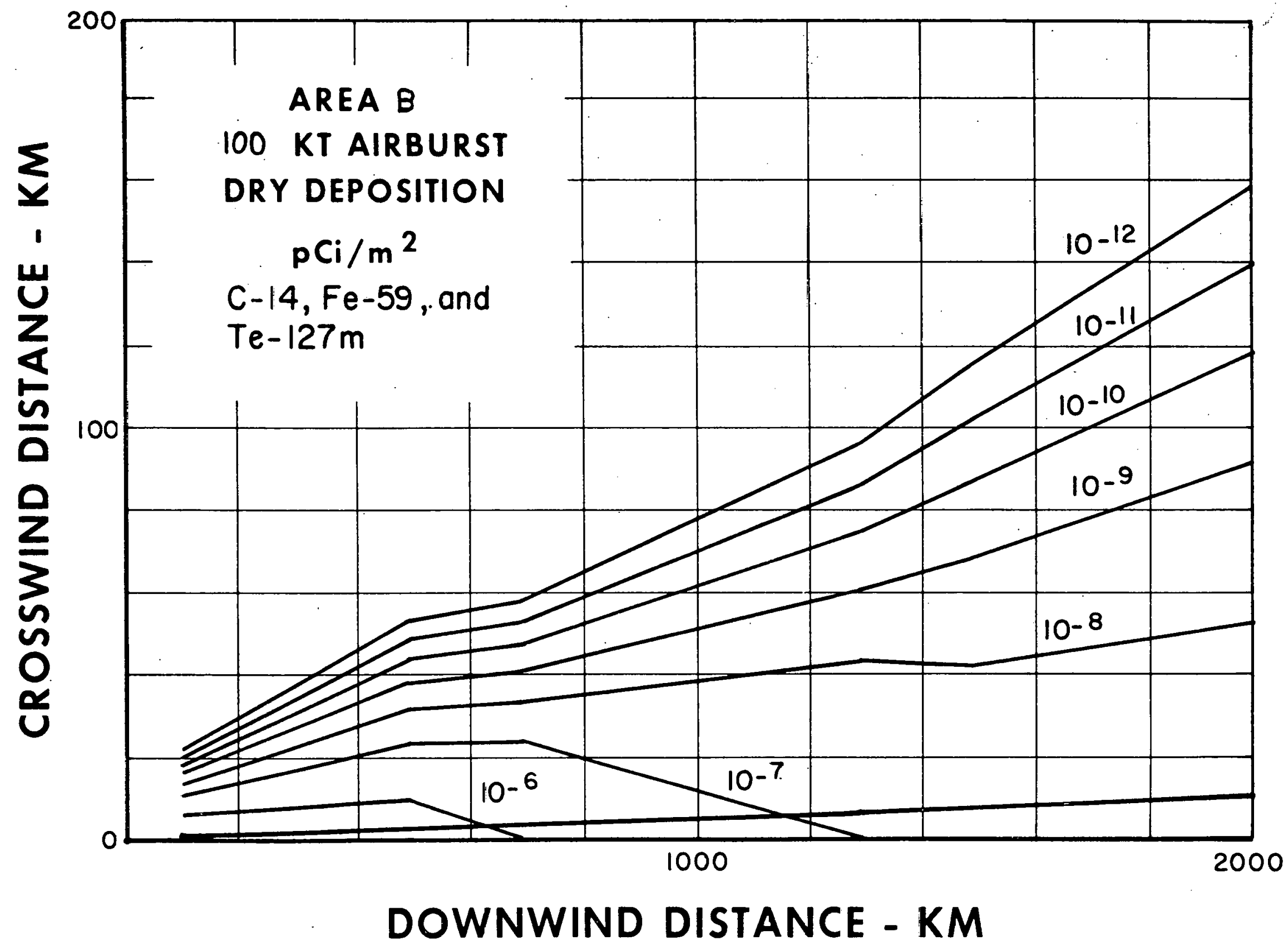




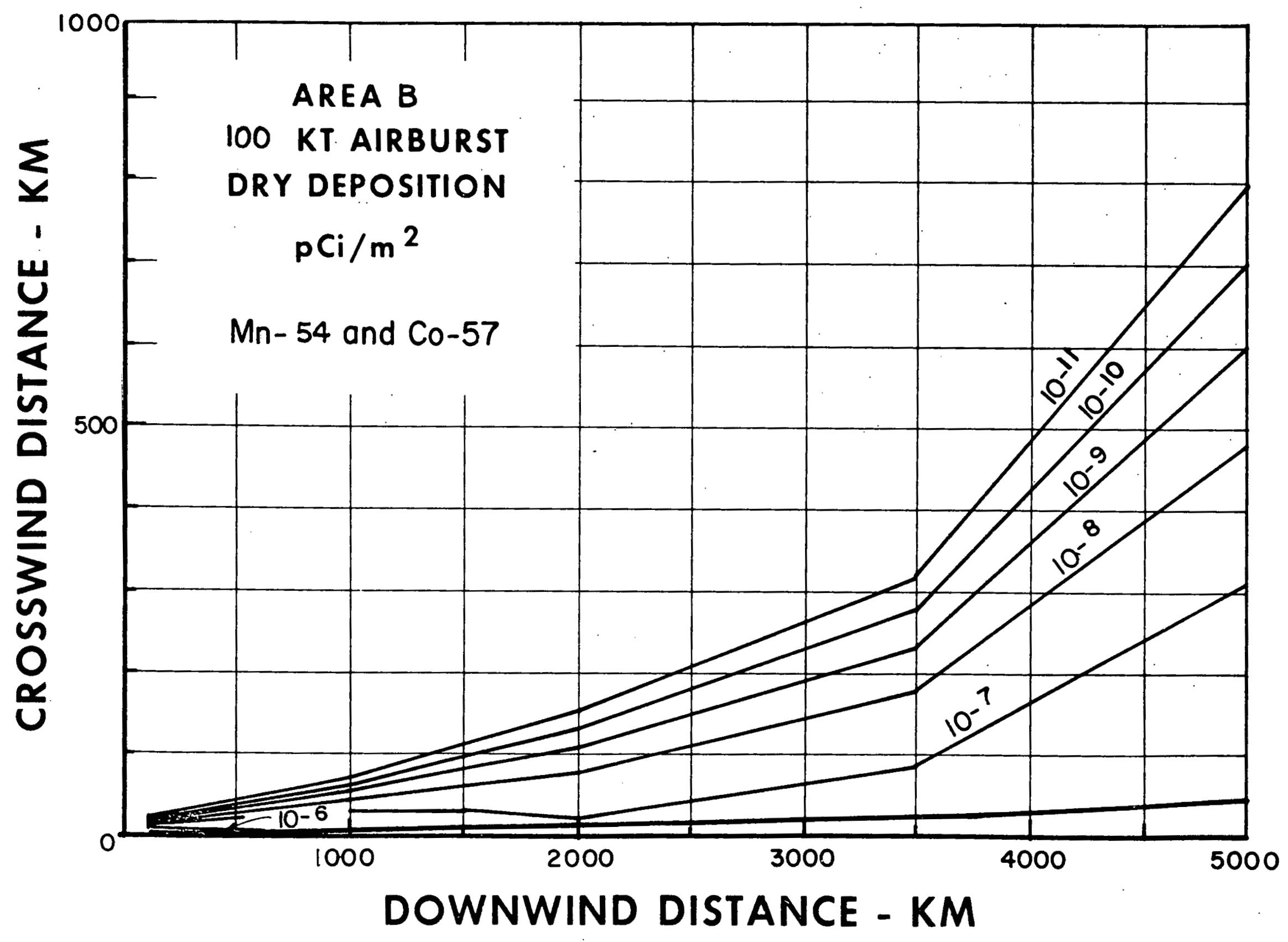




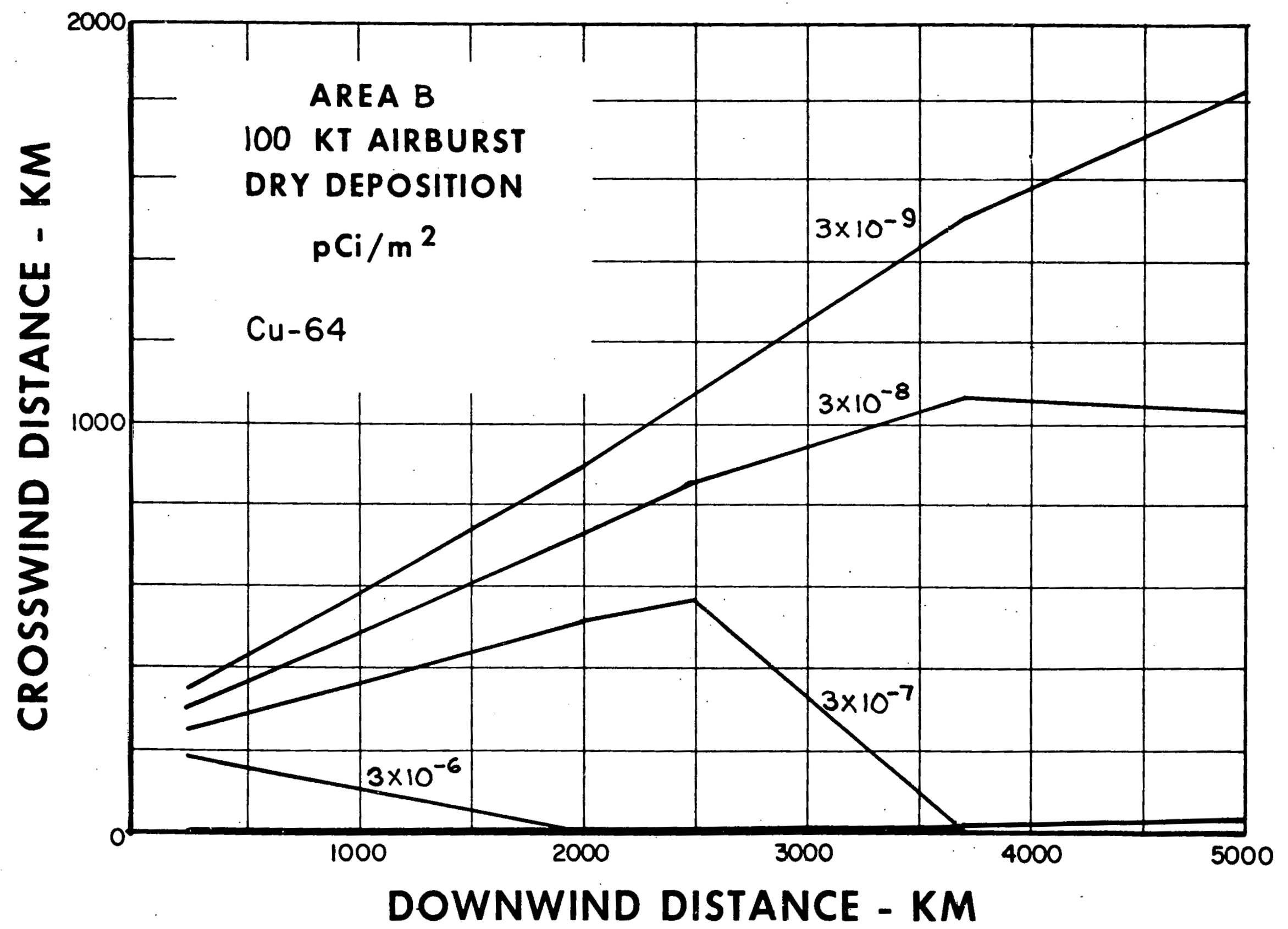




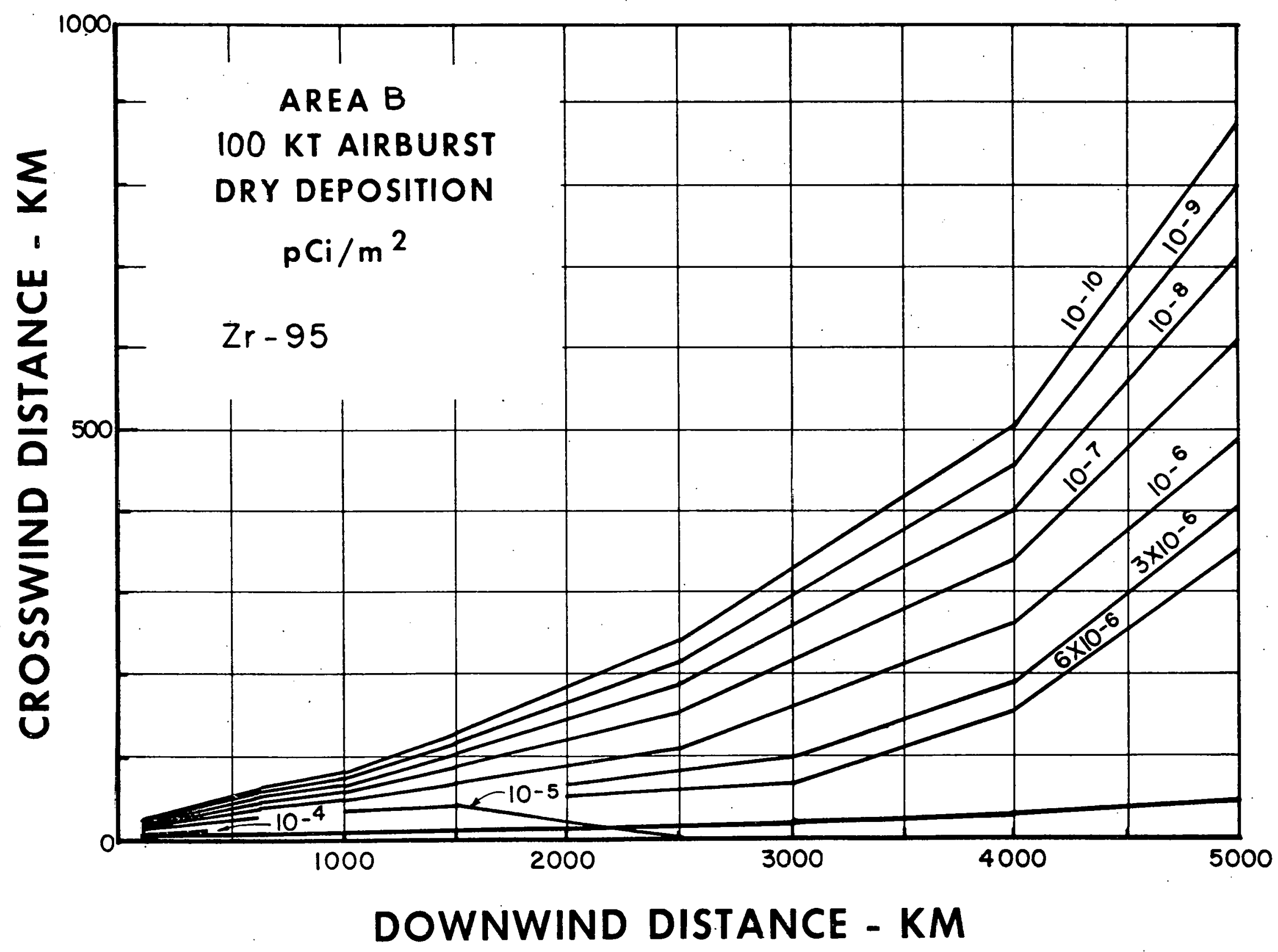




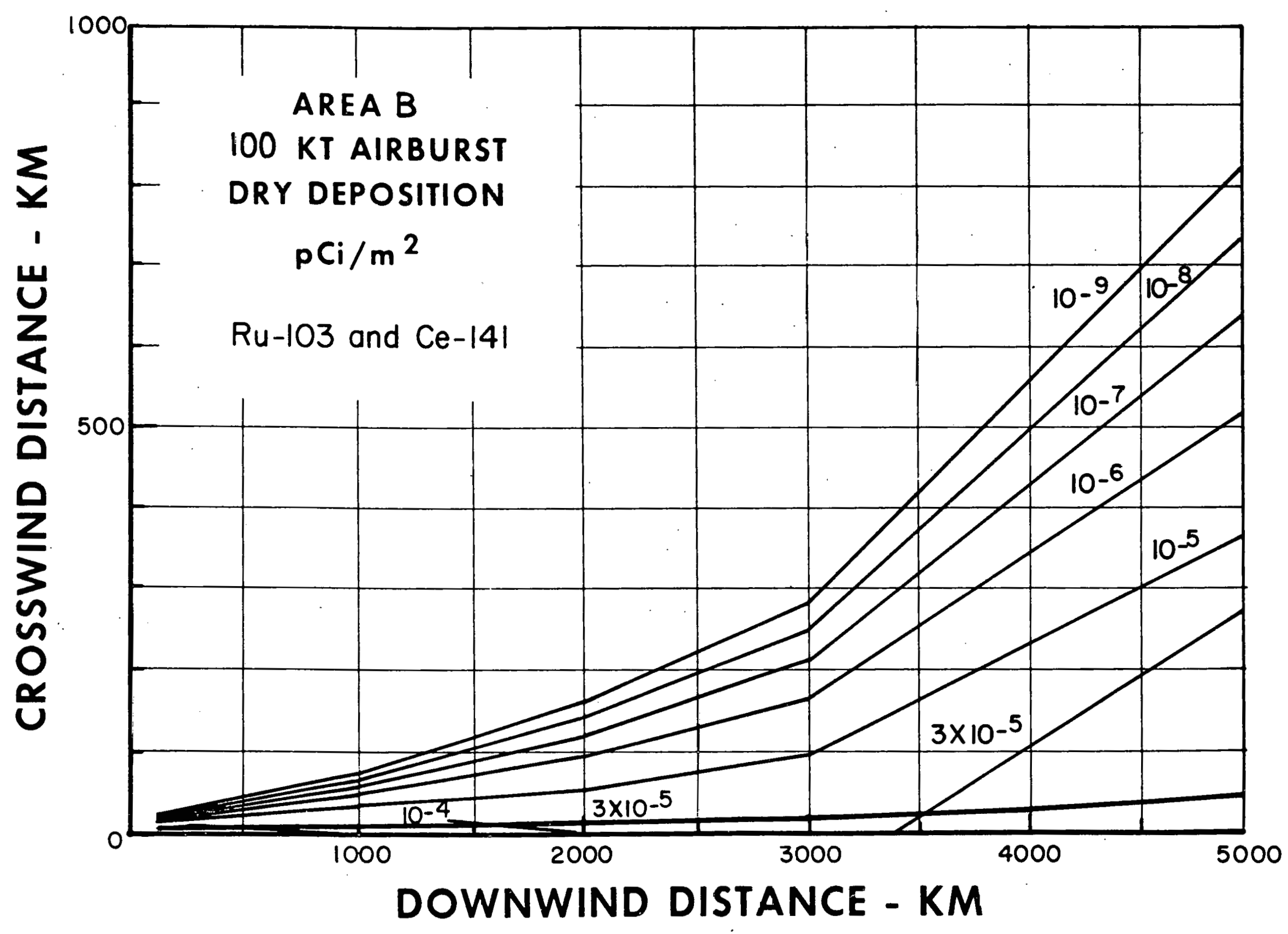




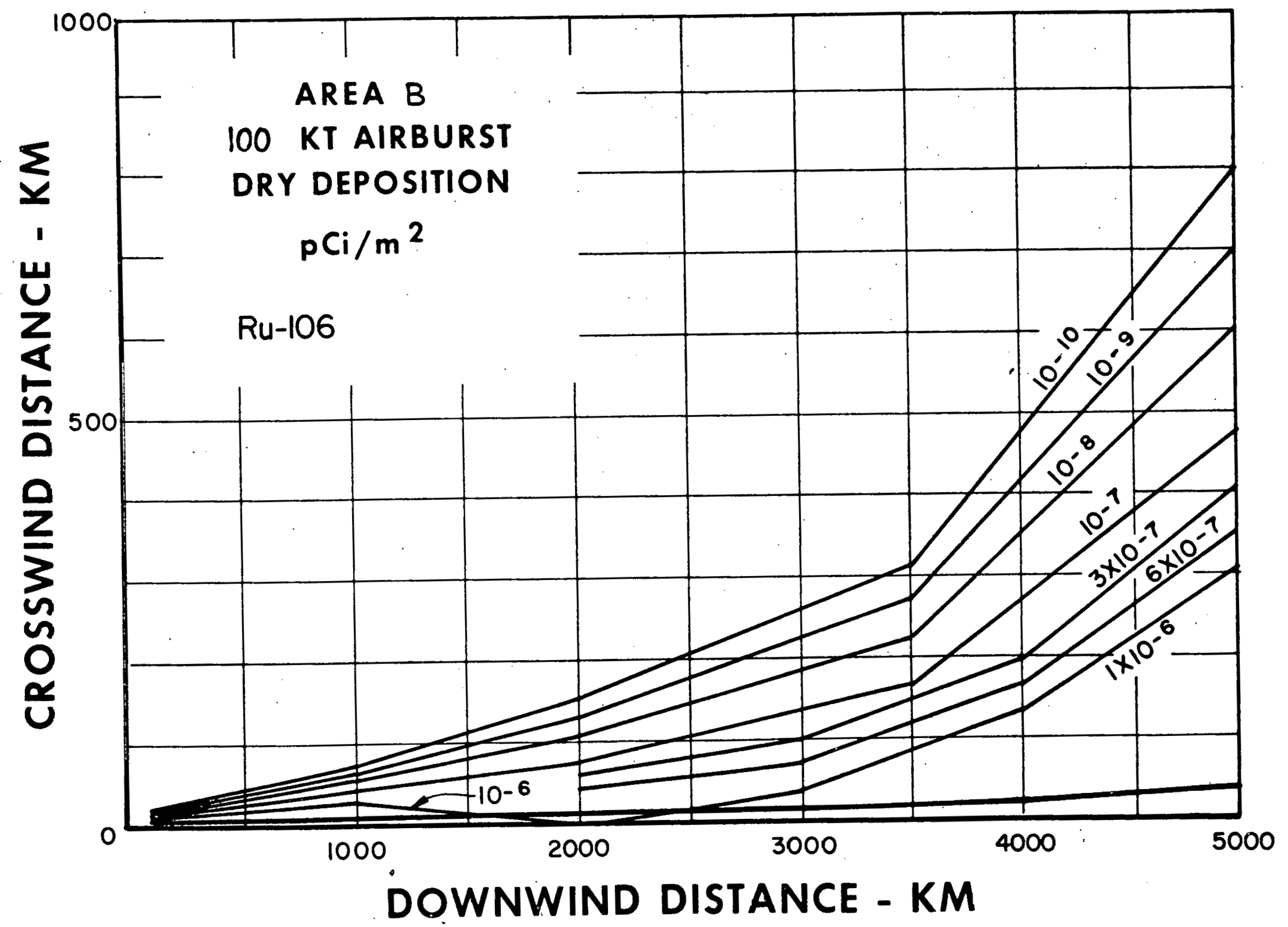




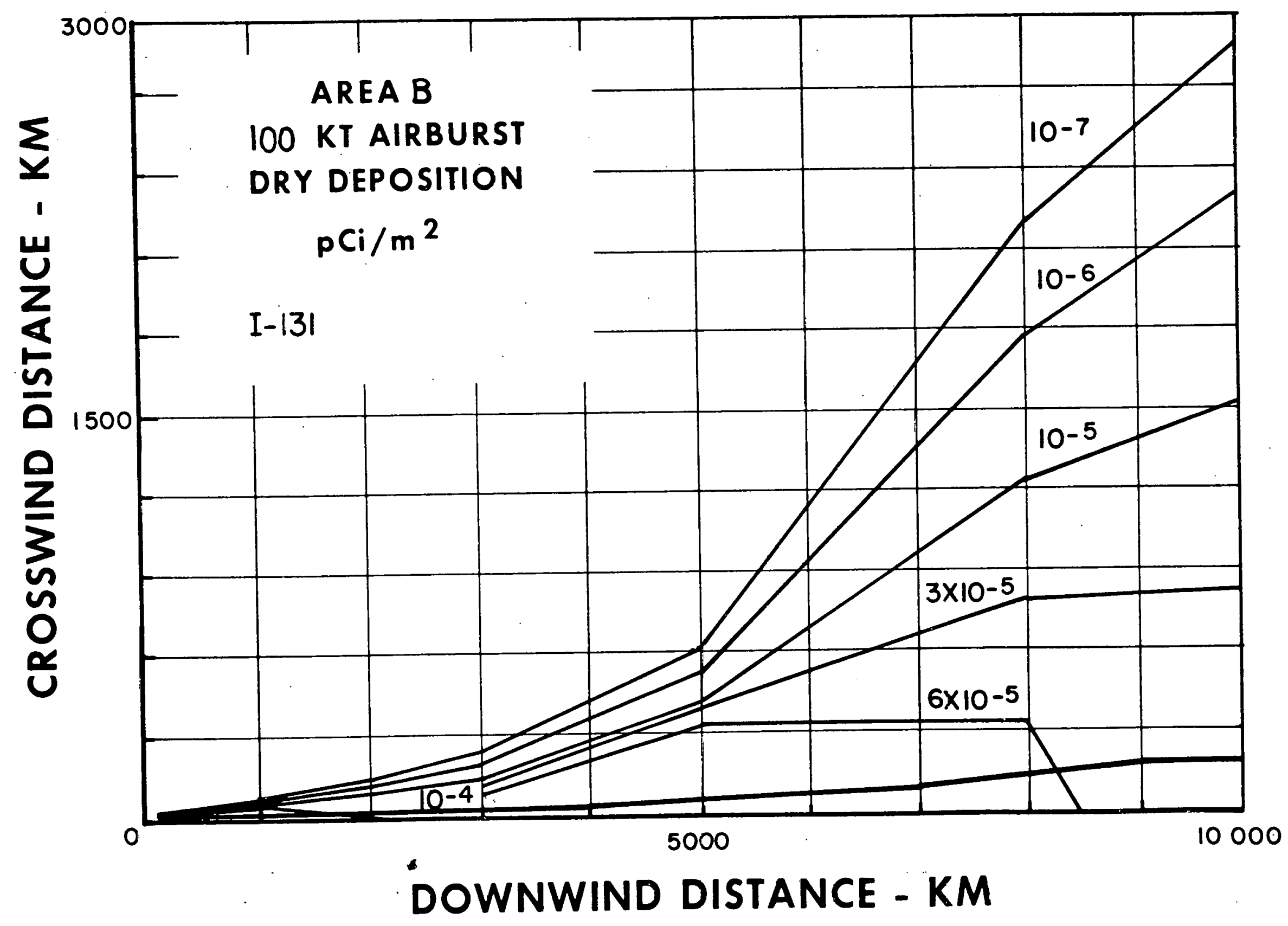




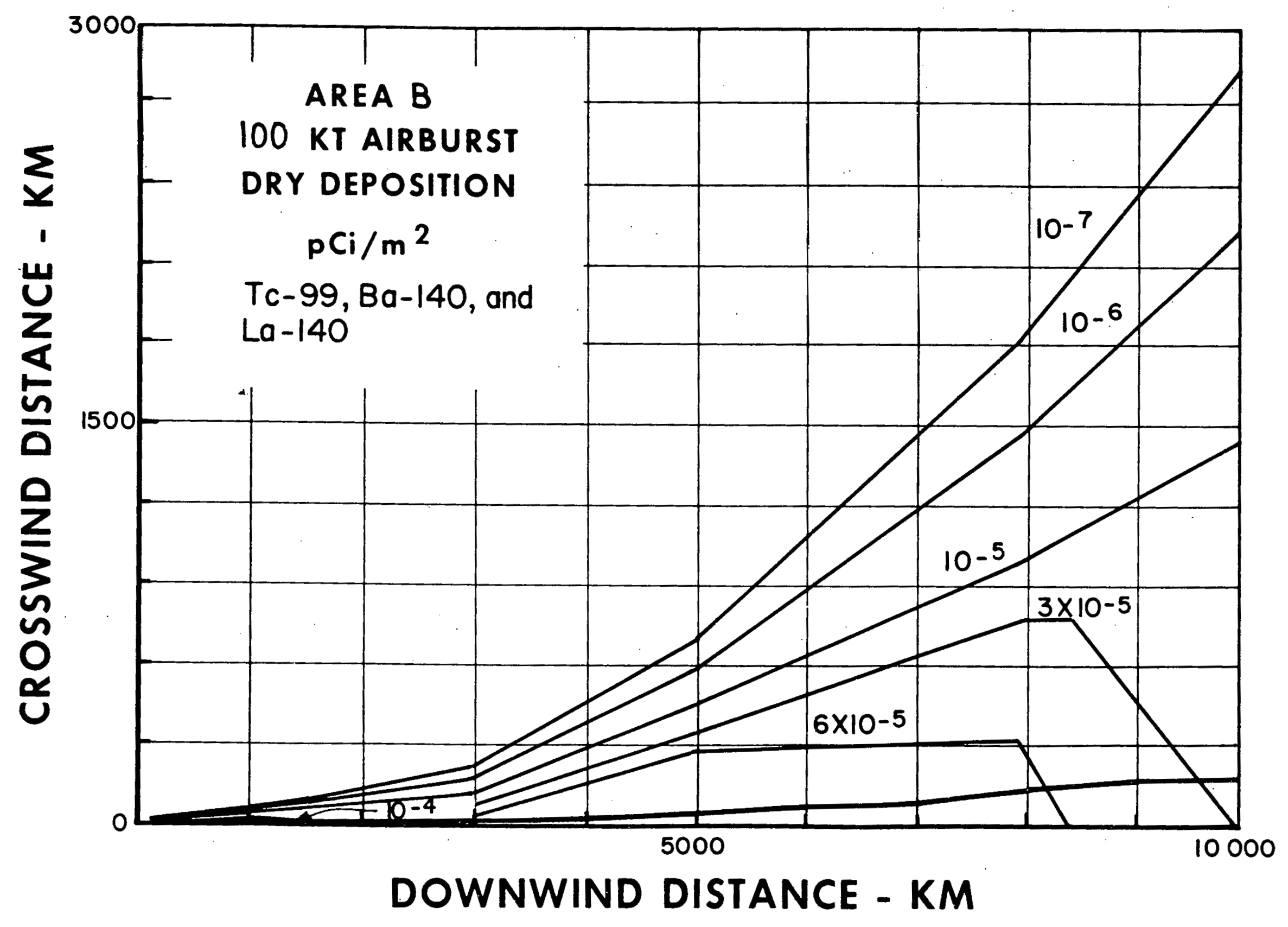




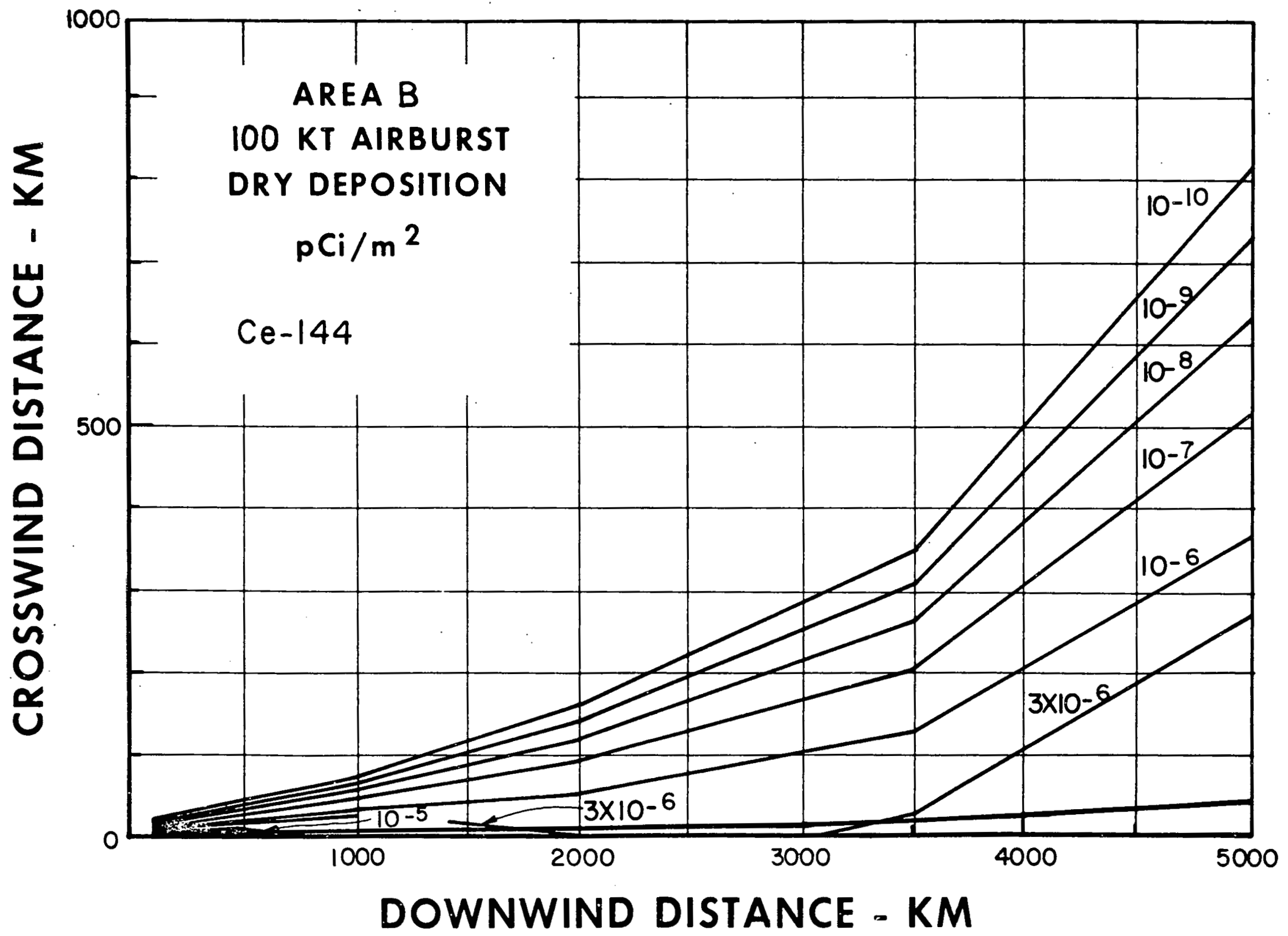




\section{REFERENCES}

1. T. V. Crawford, "A Computer Program for Calculating the Atmospheric Dispersion of Large Clouds," Lawrence Livermore Laboratory, Rept. UCRL-50179 (1966).

2. D. H. Siade, Editor, "Meteorology and Atomic Energy 1968," Sec. 5-3.2,

U. S. Atomic Energy Commission, 1968.

3. J. B. Knox, T. V. Crawford, K. R. Peterson, and W. K. Crandall, "Comparison of U.S. and U. S. S. R. Methods of Calculating the Transport, Diffusion, and Deposition of Radioactivity," Lawrence Livermore Laboratory, Rept. UCRL-51054 (1971).

4. J. B. Knox, "Prediction of Fallout from Subsurface Nuclear Detonations, Proceedings of the Second Conference on Radioactive Fallout from Nuclear Weapons Tests," CONF-765, Held at Germantown, Maryland, Nov. 3-6, 1964.

5. J. B. Knox, T. A. Gibson, and L. A. Lawson, "KDFOC: A Computer Program to Calculate Fallout from Underground and Land Surface Explosions," Lawrence Livermore Laboratory, Rept. UCRL-51179 (1972).

6. K. R. Peterson, "An Empirical Model for Estimating World-Wide Deposition from Atmospheric Nuclear Detonations, "Health Physics, Vol. 18, $357,1970$.

7. A. Seymour, private communication, 1974.

8. Y. C. Ng and H. A. Tewes, "Radionuclide Body Burdens and Hazards from Ingestion of Foodstuffs Contaminated by Fallout," Proceedings of Conference on Survival of Food Crops and Livestock in the Event of Nuclear War, CONF-700909, Held at Brookhaven National Laboratory, Sept. 15-18, 1970.

9. "Disposal of Low-Level Radioactive Waste into Pacific Coastal Waters," National Academy of Sciences, National Research Council Publication 986.

10. H. L. Crutcher, "Upper Wind Statistics Charts of the Northern Hemisphere," NAVAER 50-1C-535, Vols. I and II, Office of Chief of Naval Operations, 1959.

11. J. K. Ange11, "Use of Constant Level Balloons in Meteorology," Advances in Geophysics, Vol. 8, H. Landsberg and J. Van Mieghem, Ed., Academic Press, New York, 196T.

12. R. J. Donaldson and D. Atlas, "Radar in Tropical Meteorology," Proceedings of the Symposium on Tropical Meteorology, J. W. Hutchings, Ed. New Zealand Meteorological Service, Wellington, New Zealand, 1964 , p. $423 f f$. 


\section{REFERENCES CONTD.}

13. J. A. Day and G. L. Sternes, Climate and Weather, Addison-Wesley Publishing Company, Reading, Mass., p. 32 (1970).

14. H. A. Tewes, private communication, 1974.

15. J. R. Martin and J. J. Koranda, "The Importance of Tritium in the Civi1-Defense Context," Proceedings of Conference on Survival of Food Crops and Liverstock in the Event of Nuclear War, CONF-700909, Held at Brookhaven Nattonal Laboratory, Sept. 15-18, 1970. 


\section{DISTRIBUTION}

\section{LLL Internal}

J. Tinney

T. Gibson

E. Woodward

H. Tewes

J. Knox

P. Gudiksen

K. Peterson

TID

5.

42

\section{External}

Ross Kinnaman 5

E. M. Douthett

Nevada Operations Office ERDA

P. O. Box 14100

Las Vegas, Nevada. 89114

\section{W. A. Schwem}

Logistics Planning Group

Holmes and Narver, Inc.

P. 0. Box 14340

Las Vegas, Nevada 89114

A. H. Seymour

Laboratory of Radiation Ecology

College of Fisheries

University of Washington

Seattle, Washington 98105

J. D. Isaacs

Scripps Institution of Oceanography

University of California

P. 0. Box 1529

La Jolla, Callfornia 92037 sponsored by the United States Government. Neither the United States nor the United States Energy Research \& Development Administration, nor any of their employees, nor any of their contractors, subcontractors, or their employees, makes any warranty, express or implied, or assumes any legal liability or responsibility for the accuracy, completeness or usefulness of any information, completeness or usefulness of any information, represents that its use would not infringe orivately-owned rights." 